\title{
ARTÍCULOS DE ACTUALIZACIÓN
}

\author{
El desarrollo de la microbiota intestinal humana, \\ el concepto de probiótico y su relación \\ con la salud humana
}

\section{Development of the human intestinal microbiota, the concept probiotics and their relationships with human health}

\begin{abstract}
Probiotics are live microorganisms which, when ingested in adequate numbers, confer health benefits to the host. They originate mostly from the colonic and vaginal microbiota of humans although a number of strains originate from the environment. The human fetus is colonized after birth by bacteria of maternal fecal and vaginal origin and by microorganisms from the environment. Maternal milk contains a varied microbiota, mainly lactobacilli and bifidobacteria. After weaning the resident microbiota becomes more complex and by 2 years of age it is composed of some 1500 species with 1014 microorganisms. During the colonization of the digestive tract of premature infants low birth weight, immaturity of the defenses and artificial feeding may lead to necrotizing enterocolitis. This inflammatory condition involves mainly the terminal ileum and the colon and may result in necrosis and perforation of the wall with subsequent peritonitis. Anoxia and abnormal colonization are important associated factors. Probiotic administration is associated with a decreased risk of this condition and decreases of its morbidity, mortality and sequelae if the treatment is started early. The positive effects are associated with more than one species of probiotics. The risk of septicemia associated with probiotics has been widely discussed. Studies in Helsinki, Finland, demonstrated that the results of comparing the frequency and etiology of septicemia during the 10 years after the introduction of probiotics with the results in the 10 years previous to their introduction were not different. Septicemia due to probiotics is infrequent and most cases are associated with extreme prematurity, failure of the intestinal barrier function, heart valve disease, severe shock and congenital immune deficiencies; patients with these conditions should be closely watched if they consume probiotics. However, patients with HIV and AIDS benefit from the consumption of these microorganisms. It has nor been demonstrated that probiotics play a role in the genesis of obesity.

Key words: probiotics, maternal milk, microbiota, colonization, necrotizing enterocolitis, premature.
\end{abstract}

Los probióticos son organismos vivos que al ser ingeridos en cantidades adecuadas confieren beneficios para la salud del huésped (1). La evidencia existente indica que estas bacterias confieren beneficios en el manejo o la prevención de algunas enfermedades del tubo digestivo, de enfermedades con base inmunitaria y algunas alteraciones metabólicas (2). El origen
Oscar Brunser T.

Representante en Chile, Nestlé Nutrition Institute Santiago, Chile

Dirigir la correspondencia a:

Oscar Brunse Dr.
ser $T$. Profesor de Pediatría, Universidad de Chile Avda. Las Condes 11287 - 5'Piso - Las Condes Santiago - Chile E-mail: oscar.brunser@CL.nestle.com

Este trabajo fue recibido el 9 de Julio de 2013 y aceptado para ser publicado el 26 de Agosto de 2013.

de las bacterias probióticas es principalmente la microbiota del colon o la vagina de seres humanos aunque muchos microorganismos con estas características viven también ampliamente distribuidos en el medio ambiente. Muchas de sus propiedades derivan de haber coexistido con Homo sapiens por centenares de miles de años en un comensalismo que fue 
estimulado por su inocuidad (3).

\section{DESARROLLO DE LA MICROBIOTA INTESTINAL HUMANA}

El feto humano se desarrolla en el ambiente estéril de la cavidad uterina y su colonización comienza durante su paso por el canal vaginal y el contacto con la flora fecal materna durante el parto. Otras fuentes de bacterias para la formación de la población microbiana del tubo digestivo del recién nacido son la piel materna y el medio ambiente que lo rodea. Este último puede transmitirle incluso patógenos de diverso tipo desde los primeros días de vida (4). El proceso de colonización no sería un proceso enteramente al azar sino que seguiría una secuencia en que diferentes superfamilias de bacterias se suceden en el tiempo con la participación adicional de la leche materna que también proporciona al recién nacido diversos nutrientes, algunos de ellos con propiedades de prebióticos y antimicrobianas (5-8), además de microorganismos probióticos, como se verá a continuación.

Los probióticos y la leche materna. En un estudio de Collado y cols. efectuado en muestras de leche de 50 madres se detectó mediante PCR cuantitativa en tiempo real, (qRT$P C R)$ la presencia de diversos géneros o conjuntos (clusters) de bacterias que incluían predominantemente Staphylococcus, Streptococcus, Bifidobacterium, y Lactobacillus además de Enterococcus y Clostridium XIXa-XIVb, con frecuencias más bajas de Bacteroides y Clostridium cluster IV sólo en dos muestras. Los recuentos totales de microorganismos expresados como logaritmo decimal de los equivalentes de genoma por mililitro fueron 6,03 \pm 0,75 (aproximadamente un millón de microorganismos por ml) (9). La composición de esta microbiota varía dependiendo de la etapa y duración de la lactancia; por otra parte, la microbiota del calostro es diferente de aquella presente en la etapa de lactancia madura o de los meses finales del proceso (10). La microbiota de la leche materna depende también del estado nutricional de la madre y es menos diversa en las mujeres obesas (10).

En la leche materna han sido detectadas cepas de probióticos exógenos que han sido administrados por vía oral a la madre, como por ejemplo L. reuteri ATCC 55730 (11). De las especies de Bifidobacterium aisladas de la leche materna algunas tienen características de probióticos al evaluarlas respecto de su capacidad de resistir los efectos del ácido clorhídrico y la bilis, de su capacidad de inhibir el crecimiento de patógenos y de adherirse a líneas celulares derivadas de los enterocitos y a la mucina intestinal de lactantes; además no se detectan en su citoplasma factores de virulencia transmisibles (plasmidios) (12). Gueimonde y colaboradores identificaron en la leche humana Bifidobacterium longum, B. lactis, $B$. animalis y $B$. catenulatum con recuentos del orden de 104 UFC por ml; también fueron identificadas frecuentemente algunas especies de bacterias Gram positivas con recuentos que fueron similares o incluso algo superiores a los de algunas de las especies de bacterias antes nombradas (13). Si se tiene en cuenta que una nodriza le suministra a su hijo diariamente un volumen aproximado de $1000 \mathrm{ml}$ de leche, quiere decir que en el intestino de éste último se siembran cada día 107 microorganismos que pertenecen a distintas superfamilias, géneros, especies y cepas; queda por saber si este proceso sigue verdaderamente un plan preestablecido $y$, de ser así, qué factores rigen su progreso y cuales son sus blancos y receptores en el tubo digestivo del lactante.

Recientemente Grönlund y colaboradores observaron que al mes y a los 6 meses después del parto tanto la similitud como la diversidad de las poblaciones de bifidobacterias fecales estaba aumentada en diadas madre-hijo, en especial para Bifidobacterium bifidum, cuando las madres habían recibido por vía oral combinaciones distintivas del perfil de probióticos, siendo que estos agentes habían tenido poco efecto sobre las otras poblaciones de bifidobacterias del hijo (14).

Un aspecto que recientemente ha recibido atención es el origen de las bacterias detectadas en la leche materna. Donnet-Hughes y colaboradores demostraron en ratas que durante la lactancia se produce la migración de células dendríticas que contienen bacterias de origen colónico desde las placas de Peyer a los nódulos linfáticos mesentéricos, desde donde migrarían a la glándula mamaria a través de la circulación sanguínea y los vasos linfáticos. Este mismo grupo de investigadores demostró que en la circulación sanguínea de mujeres embarazadas transitan monocitos cuyo citoplasma contiene bacterias vivas sin inducir síntomas de bacteremia; además, en las células acinares de la glándula mamaria se detectaron bacterias o su material genético. Este fenómeno sería característico del embarazo y la lactancia y estimularía el imprinting inmune de la glándula mamaria (15).

Se ha postulado que las bacterias de origen colónico podrían formar biofilms en los galactóforos, desde los que se vaciarían al flujo de leche materna durante el amamantamiento. Se desconoce cual sería la evolución de todo este sistema con el destete, cuando se produce la involución de acinos y galactóforos.

Colonización del intestino del recién nacido. La Colonización del intestino del recién nacido parece seguir una secuencia que ha sido estudiada en detalle, aunque muchos de sus determinantes no han sido elucidados. En las primeras 24 a 72 horas después del parto el lumen del colon contiene una cierta cantidad de oxígeno y es colonizado por enterobacterias Gram-negativas provenientes de la microbiota fecal materna. Estas bacterias consumen el oxígeno y generan un ambiente anaerobio favorable para el desarrollo de los anaerobios que pasan a constituir la microbiota dominante de los niños alimentados en forma exclusiva con leche materna, con predominio de los lactobacilos y bifidobacterias y recuentos bajos de Bacteroides y enterobacteriáceas. Cuando el niño es destetado, su microbiota residente comienza a parecerse a la de los adultos, con aumentos del número y variedad de sus especies bacterianas y cepas y entre el primero y el segundo años de vida llega a una composición estable $(16,17)$. Sin embargo, pese a la diversidad detectable en la composición de la microbiota de los diversos individuos, a nivel metagenómico existe un núcleo común de especies cuya composición es más o menos constante, que tiene capacidades que le permiten realizar y regular funciones metabólicas importantes $(17,18)$.

Se ha postulado que la colonización inicial del intestino del recién nacido por bacterias fecales de origen materno y por aquellas provenientes de su leche materna cumple la misión de instruir al sistema inmune del lactante, desviando su patrón de reacción inmunitaria desde el perfil TH2, (propio de la etapa intrauterina y que genera propensión a manifestaciones alérgicas) hacia el perfil TH1, más maduro, que se asocia con la manifestación de tolerancia inmune y genera respuestas de tipo inflamatorio normal si es necesario. Además, bacterias de la microbiota intestinal potencian la calidad de la función de barrera de la mucosa intestinal así como la producción de mucina por las células caliciformes, estimula la síntesis de péptidos con actividad antimicrobiana por las células de Paneth y el desarrollo del tejido linfático asociado con el tubo digestivo, GALT (por sus iniciales en inglés, Gut-Associated 
Lymphoid Tissue) $(3,19)$.

Microbiota colónica, probióticos y enterocolitis necrosante. La enterocolitis necrosante (ECN) es la patología gastrointestinal que con mayor frecuencia representa un riesgo para los recién nacidos prematuros durante el primer mes de vida. Se caracteriza por un proceso de inflamación y necrosis de la pared intestinal que abarca diferentes extensiones del órgano y cuya profundidad puede comprometer desde la mucosa hasta el espesor total de la pared, a veces con perforaciones al peritoneo. Afecta especialmente a prematuros y de preferencia a aquellos cuyo peso de nacimiento es inferior a 1500 gramos, condición que representa el principal factor de riesgo. En las unidades de cuidados intensivos neonatales la prevalencia de la ECN va del 1 al $5 \%$ y es más alta mientras menores sean el peso de nacimiento y/o la edad gestacional. Sus factores etiológicos no se conocen con certeza y es indudablemente una enfermedad multifactorial; se estima que los principales factores causales serían la isquemia intestinal, la nutrición enteral y la presencia de enteropatógenos. En el contenido intestinal de los afectados se ha detectado la presencia de Klebsiella, Escherichia coli, Clostridium prefringens, Staphylococcus epidermidis y rotavirus. El cuadro no se manifiesta en los prematuros que no han recibido alimentación enteral y es menos frecuente en aquellos alimentados con leche materna $(20,21)$.

El cuadro afecta preferentemente el íleon terminal y el colon proximal pero en algunos casos ha llegado a afectar todo el tubo digestivo. La ECN se caracteriza por manifestaciones gastrointestinales (distensión abdominal, sensibilidad a la palpación, intolerancia a la alimentación, vómitos, sangrado rectal, masas intraabdominales, eritema de la pared abdominal) y síntomas y signos de compromiso sistémico (letargo, episodios de apnea, temperatura corporal inestable, acidosis metabólica, shock, coagulopatía intravascular diseminada, hemocultivos positivos) (20). En los exámenes por imágenes puede haber evidencias de fallas de la barrera de la mucosa (pneumatosis intestinalis cystoides), aire libre en el peritoneo y gas en los espacios periportales.

El tratamiento consiste en mantener la hidratación y el volumen circulante, administrar antibióticos, instalar nutrición parenteral, y considerar la necesidad de intervenciones quirúrgicas, si se estima necesario. Si al paciente se le han instalado catéteres umbilicales estos deben ser retirados y se debe utilizar otras vías para obtener acceso intravenoso. De los pacientes en quienes se ha detectado la presencia de pneumatosis intestinalis cystoides, el tratamiento médico falla en el $20-40 \%$ y de estos fallece el $10-30 \%$. Muchos pacientes requieren resecciones intestinales de diversa magnitud y una proporción de ellos queda con un síndrome de intestino corto y otros problemas de manejo difícil y prolongado. Algunos pacientes quedan con estenosis intestinales más o menos localizadas como resultado de los procesos de cicatrización $(20,22)$.

En 1999 Hoyos publicó un estudio en el que comunicó haber administrado diariamente una cantidad aproximada de 2,5 $\times 108$ de L. acidophilus e igual cantidad de Bifidobacterium infantis (Inflorán, Swiss Serum and Vaccine Institute, Bern, Switzerland) disueltos en $1 \mathrm{ml}$ de agua destilada estéril o de glucosa al $5 \%$ en agua. Este estudio incorporó a 1237 recién nacidos recibidos en una unidad de cuidados neonatales intensivos (NICU) (23). Los criterios aplicados para el diagnóstico de ECN fueron similares a los publicados por Kanto en 1994 (22). La incidencia de ECN en el grupo tratado fue un tercio de la que se detectó en los pacientes que no recibieron Inflorán
(19 vs 38; $p<0,03)$. El descenso de la mortalidad fue también importante (7 casos en el grupo que recibió Inflorán vs 25 el grupo control). La autora no consideró que la administración de los probióticos haya estado asociada con complicaciones y, por el contrario, estimó que los afectados toleraron la alimentación en mejor forma y presentaron menos dermatitis del pañal. En los tratados con Inflorán se detectó una disminución de los brotes de diarrea que afectaban a grupos de prematuros.

Después de la publicación de Hoyos aparecieron otros estudios en los que se han empleado diferentes probióticos y se han efectuado metaanálisis para evaluar conjuntos de resultados y acumular de esta manera números más altos de participantes, consiguiendo con ello mayor poder estadístico. En general estos estudios incorporaron prematuros con menos de $1500 \mathrm{~g}$ de peso de nacimiento o tenían edades gestacionales entre 27 y 34 semanas.

En un metaanálisis publicado en 2006, Szajewska y colaboradores sostuvieron que habría una sólida racionalidad en el uso de probióticos en la prevención de la ECN en recién nacidos de pretérmino evidenciada en estudios con distribución aleatoria y con grupo control (RCT) que demuestran la eficacia de los probióticos, lo que representa un avance significativo en su manejo y en la prevención de la ECN. Teniendo en cuenta el riesgo potencial que podría involucrar la administración de grandes dosis de bacterias vivas a lactantes inmaduros en numerosos de sus aspectos funcionales, Szajewska y colaboradores estimaron aconsejable efectuar estudios multicéntricos. Además Ilamaron la atención a la ocurrencia de algunos casos de sepsis en prematuros afectados por cuadros sistémicos de considerable gravedad (24). Después de esta publicación se ha acumulado un número considerable de estudios recientes. Una revisión efectuada por un grupo de especialistas encabezado por la misma autora en 2010, en el que se evaluó el efecto de Bifidobacterium animalis subsp. lactis en 324 lactantes de pretérmino, demostró que este probiótico no tenía efecto cuando la ECN había alcanzado etapas muy avanzadas, con presencia de sepsis o uso de antibióticos. La administración de probióticos disminuyó los recuentos de Enterobacteriaceae y Clostridium spp en las heces, indujo descensos de la calprotectina fecal (proteína de los neutrófilos que se considera evidencia de la presencia de inflamación intestinal), estimula aumentos de la IgA secretoria y de los ácidos grasos de cadena corta fecales y disminuye la permeabilidad intestinal. No se observaron efectos adversos atribuibles al B. lactis. En esa misma evaluación se sostiene que el empleo de B. lactis en prematuros da motivos para ser optimista y que es probable que estimule una disminución del riesgo de desarrollar ECN (25).

En 2003 - 2005 Mohan y colaboradores evaluaron los efectos de la administración de Bifidobacterium lactis Bb12 en un estudio en doble ciego, randomizado y controlado con placebo que incluyó 69 recién nacidos de pretérmino con menos de 37 semanas de gestación. La dosis de probiótico administrada fue 1,6 × 109 en los días 1-3 y 4,8 × 109 a partir del día 4, la que fue agregada a la leche materna junto con un una mezcla de fortificantes. De los prematuros que participaron en el estudio, 46 debieron recibir cefotaxima, vancomicina o imipenem en vista de su evolución clínica (26). En los niños que recibieron antibióticos, la administración del probiótico se asoció con un mayor incremento del peso corporal pese a que los niños del grupo control consumieron mayores volúmenes de fórmula. El $\mathrm{pH}$ de las heces de los prematuros que recibieron el probiótico era más bajo que en los controles y en ellas las concentraciones de ácidos grasos de cadena corta, 
acetato, propionato, butirato y lactato, eran más altas que en los controles; sin embargo, los perfiles de estos ácidos grasos eran semejantes en ambos grupos; la concentración de lactato fecal era más elevada en los prematuros que no recibieron antibióticos. Los niveles de calprotectina en las deposiciones eran significativamente más elevados en el grupo control pero esta diferencia desaparecía cuando se comparaba a quienes habían sido tratados con antibióticos. La IgAs fecal estaba más elevada en los niños que recibieron Bb12 desde las dos primeras semanas aunque esta diferencia se observaba solamente en quienes no habían sido tratados con antibióticos. Los autores postularon que en los prematuros la administración de Bb12 se asoció con parámetros fecales que indican que el probiótico induce procesos fermentativos beneficiosos para la salud, se asocia con disminuciones de algunos parámetros indicadores de fenómenos inflamatorios intestinales $y$, al ser administrado junto con antibióticos, estimula la ganancia de peso (26).

Un grupo de autores australianos (27-30) efectuó varios metaanálisis de publicaciones que discutían el efecto de los probióticos en la evolución de los prematuros nacidos con menos de 33 semanas de gestación. Las 7 publicaciones seleccionadas por ellos satisfacían estrictos criterios de selección, usaron metodología de doble ciego, control con placebo y asignación al azar. El primer metaanálisis incorporó 1393 niños (27) y los autores concluyeron que en prematuros menores de 33 semanas los probióticos disminuirían el riesgo de ECN y la mortalidad y acortaron el intervalo requerido para alcanzar la alimentación oral total. En cambio, el riesgo de sepsis fue semejante al comparar a los controles y los niños que recibieron probióticos. Una ventaja y al mismo tiempo una desventaja de este metaanálisis fue que los probióticos evaluados fueron variados: Bifidobacterium breve, Lactobacillus rhamnosus GG, Saccharomyces boulardii, una mezcla de Bifidobacterium infantis, Streptococus thermophilus y Bifidobacterium bifidus, Lactobacillus acidophilus y Lactobacillus casei. Por otra parte, los estudios se llevaron a cabo en diversos continentes, países y grupos étnicos, lo que aumenta su valor. Los autores recomendaron ejercer cautela en el uso de probióticos en prematuros ya que se desconocen los posibles efectos que pudieran tener a corto y/o largo plazo. En su segunda publicación, a los 7 estudios evaluados en la publicación anterior se adicionaron 4 más, lo que elevó el total de prematuros involucrados a 2176. La administración de probióticos disminuyó el riesgo de ECN ( $p<0.00001)$, el riesgo de sepsis continuaba sin variación en tanto que la mortalidad disminuyó ( $p<0,00001$ ) y el período de tiempo necesario para alcanzar la alimentación enteral total también fue más breve ( $p<0.0001)$. El análisis secuencial total (TSA, Total Sequential Analysis) demostró que en los prematuros que reciben probióticos se produce una disminución del riesgo de $\mathrm{ECN}$ de $30 \%$ (con $\mathrm{a}=0,05$ y un poder $\mathrm{b}$ de $80 \%$ ). Sin embargo, no se sabe si el riesgo de sepsis de aparición tardía disminuye. Los autores señalan que los probióticos pueden actuar porque en los prematuros interfieren con la colonización del intestino por patógenos como el estafilococo coagulasa negativo, que es el microorganismo que con mayor frecuencia se asocia con procesos de sepsis, aunque sigue siendo muy frecuente que haya colonizaciones anormales de territorios donde se han insertado catéteres: endotraqueales, venosos centrales, en las venas umbilicales o venas donde se realizan infusiones intravenosas de líquidos con diversas composiciones (28). Un hecho respecto del cual Ilaman la atención es la ausencia de sepsis inducida por los probióticos administrados, pese a que los números de microorganismos administrados son muy elevados (miles de millones de UFC por día).
La administración de los probióticos no parece alterar negativamente el desarrollo neurológico de los prematuros y, por el contrario, al disminuir la incidencia de sepsis permitirían mejorar la calidad de su nutrición, lo que tendría efectos positivos. En este segundo estudio los autores sostienen que los probióticos deberían ser ofrecidos como un tratamiento rutinario para los recién nacidos prematuros y que en los estudios futuros no se debería recurrir al uso de grupos control sin probióticos. Los mismos autores mantienen que, aclarado este aspecto, se debería proceder a afinar la información referente a especies de probióticos, cepas, recuentos de microorganismos y los protocolos para su aplicación. Estos aspectos fueron discutidos posteriormente en dos publicaciones adicionales de los mismos autores $(29,30)$ quienes consideran que se debería preferir a las bifidobacterias y que probablemente los lactobacilos no serían efectivos; la dosis a administrar debería ser 3 x 109 UFC una vez al día cuando el prematuro esté en condiciones de recibir alimentación enteral, preferiblemente dentro de los 7 primeros días de vida y se debería mantener dicha administración hasta la semana 35 corregida o hasta el alta. La administración se debería suspender si se produce una enfermedad aguda, como por ejemplo un episodio de sepsis, si aparece ECN de grado avanzado o en presencia de asfixia perinatal (31).

Una publicación reciente, que incluye el metaanálisis de 20 publicaciones coincide en sus resultados y conclusiones con lo sostenido por Deshpande, Patole y cols. (32). Por otra parte, una revisión sistemática publicada recientemente por la American Pediatric Surgical Association, Outcomes and Clinical Trials Committee, apoya el uso de probióticos en el manejo de los prematuros, en especial de aquellos con menos de 1500 gramos de peso de nacimiento. Al mismo tiempo, esta entidad recomienda la alimentación de estos prematuros con leche materna ya que está asociada con un menor riesgo de ECN (33).

Es posible que la presencia de la leche humana, que también posee una microbiota propia con bacterias que tienen la característica propias de probióticos, ejerza efectos sinérgicos en estos procesos (34). En conclusión, los probióticos ejercen efectos que pueden ser definidos como preventivos; queda por determinar cuales son las especies y las cepas que son más eficientes en este sentido.

Hay dos aspectos que han sido objeto de discusiones: a) la posibilidad de que en algunos individuos los probióticos invadan la circulación sanguínea produciendo cuadros sépticos $y, b)$ que estas bacterias tengan un papel en la génesis de la obesidad.

Septicemia por bacterias probióticas: ¿un riesgo verdadero?. La posibilidad de la ocurrencia de septicemias asociadas con la administración de probióticos ha sido motivo de preocupación y discusión desde que se inició su uso masivo. Sin embargo, vale la pena tener en cuenta que grandes números de individuos consumen probióticos sin indicación ni control médico de ningún tipo y sin experimentar mayores problemas de salud. La presentación más frecuente de esta patología es la sepsis asociada principalmente con la detección de Lactobacillus de distintas especies y cepas en los hemocultivos. Los pacientes afectados con mayor frecuencia son los prematuros extremos, especialmente aquellos con ECN en sus diferentes etapas de evolución. Por lo demás, en algunos centros se han utilizado diversos probióticos, especialmente Lactobacillus GG, con buenos resultados para la prevención de la colonización y septicemia por Candida en prematuros (35). Las cardiopatías congénitas parecen estar asociadas con aumentos del riesgo 
de sepsis por lactobacilos en prematuros y lactantes menores, aunque los probióticos estaban asociados con una fracción muy menor del número total de episodios (36).

Existe consenso en el sentido que se debe ser extremadamente cauto en el empleo de estos agentes en pacientes críticos (37). No respetar esta precaución básica produjo considerable morbilidad y mortalidad en un grupo de adultos a quienes se administró una mezcla de probióticos y presentaban cuadros de pancreatitis aguda con quistes y colecciones de exudados, shock, falla multiorgánica y de la función de barrera intestinal. Este estudio produjo intenso rechazo por numerosos grupos de especialistas debido a los defectos del diseño experimental dada la condición crítica, casi terminal de la mayoría de los pacientes tratados. Los investigadores debieron interrumpir el estudio ante la alta mortalidad que se produjo (38).

Pacientes con infección por $\mathrm{VIH}$ e incluso con SIDA consumen probióticos sin sufrir perjuicios y al contrario, con beneficios en cuanto a mejorías de las defensas de la mucosa intestinal y del crecimiento en el caso de los lactantes contagiados (39). Es interesante anotar que aproximadamente $2 \%$ de la población es portadora de deficiencia genética de IgA tanto circulante como secretoria y sin embargo muchos de estos individuos, de distintas edades, consumen probióticos sin mayores problemas. Un seguimiento de 7 años de los casos de bacteremia asociada con el consumo de lactobacilos probióticos efectuado en Estocolmo a partir de 1998 demostró que su incidencia no varió durante dicho período y en cada año representó menos del $1 \%$ del total de casos reportados. Lactobacillus rhamnosus GG no fue detectado en ningún caso (40).

Los casos de septicemia asociados con la presencia de Bifidobacterium son extremadamente raros; recientemente se publicó el caso en un prematuro extremo con ductus arteriosus persistente. El hemocultivo anaerobio fue positivo para Bifidobacterium longum y respondió a la administración de antibióticos; seis semanas después de este episodio se produjo una estenosis inflamatoria en el colon izquierdo que fue manejada con una colostomía (41). Este Bifidobacterium puede haber sido de origen endógeno.

Se desprende que habría que ejercer cautela en la prescripción de cualquier probiótico en los sujetos que están sometidos a terapias inmunosupresoras intensas ya que en ellos se producen fallas intensas de la capacidad de barrera de la mucosa intestinal; es posible que las distintas especies y/o cepas tengan diferentes capacidades de invadir el torrente circulatorio. Con todo, la incidencia de bacteriemia o de fungemia parece ser muy baja $(39,42-44)$.

Probióticos y obesidad. Un aspecto que también ha merecido atención recientemente es la posible relación entre la microbiota colónica y la obesidad. La obesidad está asociada con cambios de la microbiota residente, con disminuciones de los miembros del filum Bacteroidetes y aumentos del filum Firmicutes (45). Se ha postulado que esta microbiota tendría una mayor capacidad de extraer energía de las fracciones no digeribles de los nutrientes que Ilegan al colon (46). Cuando los obesos pierden peso, la relación entre los dos fila se normaliza, con aumento de los Bacteroidetes y descensos de los Firmicutes (45), lo que guarda relación con la magnitud de la pérdida de peso y no con la composición de la dieta. Cambios semejantes de la proporción entre Firmicutes y Bacteroidetes han sido observados en la flora del colon de obesos en Chile, quienes también presentaban signos de laboratorio de la existencia de un proceso inflamatorio de baja intensidad evidenciado por el aumento de la proteína C-reactiva circu- lante (47). Sin embargo, no se conoce con precisión si esta asociación es un fenómeno tiene una relación causal o es parte de un proceso respecto de cuyo significado la información de que se dispone es escasa y aislada.

Raoult sugirió que, a pesar de todo, existiría algún tipo de relación entre la microbiota de los seres humanos y la obesidad (48), lo que ha sido negado por otros investigadores (49, 50). Recientemente en un modelo experimental en ratas con obesidad inducida por una dieta con alto contenido de grasa se demostró que Bifidobacterium breve B-3 ejercía efectos antiobesidad e inducía disminuciones de la acumulación de la grasa corporal total, a nivel de las almohadillas de grasa epididimaria y que induciría mejorías de los perfiles de lípidos en el plasma sanguíneo. Además, en estos animales los genes que regulan la sensibilidad a la insulina se encontraban activados (51).

De manera que a partir del nacimiento en el tubo digestivo del recién nacido se va estableciendo una microbiota bacteriana intestinal que va evolucionando con el tiempo hasta alcanzar su madurez, es decir, una composición de sus fila, géneros, especies y cepas similar a la de los adultos. Esta microbiota es modulada por diversos factores que modifican su composición: la microbiota colónica y vaginal maternas, el medio ambiente de la sala de parto, las bacterias de la leche materna, las bacterias de los alimentos no lácteos después del destete y los contactos con otros seres humanos. Diversos fármacos (como los antibióticos), alimentos y nutrientes (como el hierro, el zinc y los núcleotidos), moléculas indigeribles y fermentables (prebióticos, mucinas) y por último bacterias agregadas a alimentos o administradas en preparaciones farmacéuticas (los probióticos) pueden modular en algún momento u otro la composición de dicha microbiota y ejercer diversos efectos favorables para quien los consume. En el caso de los prematuros existe un consenso bastante amplio de que los probióticos son beneficiosos para evitar la progresión de la enterocolitis necrosante, que es una de las causas más importantes de morbilidad y mortalidad en estos niños. Las dudas acerca del riesgo de bacteremia por probióticos parece haber sido contestada en el sentido de que el riesgo es bajísimo, del orden de una fracción de 1:100.000.

La comprensión de estos aspectos ha ayudado y ayudará a mejorar el manejo del bienestar gastrointestinal de sanos y de enfermos.

\section{RESUMEN}

Los probióticos son microorganismos vivos que al ser ingeridos en cantidades adecuadas confieren beneficios para la salud del huésped. Provienen mayormente de la microbiota del colon de seres humanos aunque algunas cepas provienen del ambiente. El colon del recién nacido es colonizado durante el parto por bacterias provenientes de las microbiotas fecal y vaginal maternas, del ambiente y por lactobacilos y bifidobacterias de la leche materna. Con el destete esta microbiota se hace compleja y desde los 2 años de edad alberga unas 1500 especies y recuentos de 1014 bacterias. En la colonización del tubo digestivo de los prematuros el bajo peso de nacimiento, la inmadurez de las defensas y la alimentación artificial cuando la madre es incapaz de amamantar, llevan en una proporción de los casos a la enterocolitis necrosante, que puede afectar la pared ileal o colónica, con perforación y peritonitis en algunos prematuros. La colonización microbiológica anormal jugaría un papel importante. Los probióticos disminuyen el riesgo de este cuadro y su morbilidad y mortalidad en los casos iniciales y de intensidad media. Estos efectos positivos son causados 
por diferentes probióticos. El riesgo de septicemia asociado con los probióticos ha sido ampliamente discutido. Estudios en Finlandia no han demostrado que durante 10 años de su consumo masivo se produjeran aumentos de su incidencia ni cambios de su etiología en comparación con resultados previos a su introducción. Las septicemias han sido detectadas principalmente en individuos con graves alteraciones de su salud, pérdida de la función de barrera de su mucosa intestinal, trastornos congénitos graves de la inmunidad, lesiones valvulares cardíacas o en estado de shock. Los pacientes con $\mathrm{VIH}$ y/o SIDA se benefician con el consumo de estos agentes. No se ha demostrado que el consumo de probióticos esté asociado causalmente con la obesidad.

Palabras clave: probióticos, leche materna, microflora, colonización, enterocolitis necrosante, prematuros.

\section{BIBLIOGRAFIA}

1. WHO/FAO. 2001. Joint FAOWHO Expert Consultation: Safety assessment of foods derived from genetically modified microorganisms. En: WHO y FAO, eds. WHO/SDE/ PHE/FOS/01.3.Ed. pags. 1-28.

2. Marteau $P$, Cuillerier E, Meance $S$, Gerhardt MF, Myara A, Bouvier M, Bouley C, Tondu F, Bommelaer G, Grimaud JC. Bifidobacterium animalis strain DN-173 010 shortens the colonic transit time in healty women: a double-blind, randomized, controlled study. Aliment Pharmacol Ther 2002; 16: 587-93.

3. Wilson $M$. The gastrointestinal tract and its indigenous microbiota. En Microbial inhabitants of humans. Their ecology and role in health and disease. University of Cambridge Press. 2005; 251-317.

4. Spencer E, Araya M, Sandino AM, Pacheco I, Brunser O. Faecal excretion of rotavirus and other enteropathogens in newborns of the high and low socio-economic stratum in Santiago, Chile. Epidemiol Infect (Oxford) 1988; 101: 425-36.

5. Bode, L. Human milk oligosaccharides: prebiotics and beyond. Nutr Rev 2009; 67 (Suppl 2): S183-191.

6. Rudloff, S., G. Pohlentz, C. Borsch, M. J. Lentze and C. Kunz. 2012. Urinary excretion of in vivo (1)(3)C-labelled milk oligosaccharides in breastfed infants. Br J Nutr 107: 957-63.

7. Schwab, C. and M. Ganzle. 2011. Lactic acid bacteria fermentation of human milk oligosaccharide components, human milk oligosaccharides and galactooligosaccharides. FEMS Microbiol Lett 315: 141-8.

8. Fernández L, Langa $S$, Martín V, Maldonado A, Jiménez $E$, Martín $R$, Rodríguez JM. The human milk microbiota: Origin and potential roles in health and disease. Pharmacol Res 2012 Sep 10. pii: S1043-6618(12)00165-X.

9. Collado MC, Delgado S, Maldonado A, Rodríguez JM. Assessment of the bacterial diversity of breast milk of healthy women by quantitative real-time PCR. Lett Appl Microbiol 2009; 48: 523-28.

10. Cabrera-Rubio $R$, Collado MC, Laitinen $K$, Salminen $S$, Isolauri E, Mira A. The human milk microbiome changes over lactation and is shaped by maternal weight and mode of delivery. Am J Clin Nutr 2012; 96: 544-51.

11. Abrahamsson TR, Sinkiewicz $G$, Jakobsson T, Fredrikson $M$, Björkstén B. Probiotic lactobacilli in breast milk and infant stool in relation to oral intake during the first year of life. J Pediatr Gastroenterol Nutr 2009; 49: 349-54.

12. Arboleya S, Ruas-Madiedo P, Margolles A, Solís G, Salminen
S, Reyes-GAvilán CG, Gueimonde M. Characterization and in vitro properties of potentially probiotic Bifidobacterium isolated from breast-milk. Int J Food Microbiol 2011; 149: 28-36.

13. Zivkovic AM, German JB, Lebrilla CB, Mills DA. Human milk glycobiome and its impact on the infant gastrointestinal microbiota. Proc Natl Acad Sci 2011; 108 Suppl 1:4653-58. Gueimonde M, Laitinen K, Salminen S, Isolauri E. Breast milk: a source of bifidobacteria for infant gut development and maturation? Neonatology 2007; 92: 64-6.

14. Grönlund MM, Grześkowiak $t$, Isolauri E, Salminen S. Influence of mother's intestinal microbiota on gut colonization in the infant. Gut Microbes 2011; 2: 227-33.

15. Donnet-Hughes A, Perez PF, Doré J, Leclerc M, Levenez $F$, Benyacoub J, Serrant $P$, Segura-Roggero I, Schiffrin EJ. Potential role of the intestinal microbiota of the mother in neonatal immune education. Proc Nutr Soc 2010; 69: 407-15.

16. Mackie RI, Sghir A, Gaskins HR. Developmental microbial ecology of the neonatal gastrointestinal tract. Am J Clin Nutr 1999; 69: 1035S-45S.

17. Turnbaugh PJ, Hamady $M$, Yatsunenko $T$, Cantarel $B L$, Duncan $A$, Ley RE, Sogin $M L$, Jones WJ, Roe BA, Affourtit $J P$, Egholm M, Henrissat $B$, Heath AC, Knight $R$, Gordon Jl. A core gut microbiome in obese and lean twins. Nature 2009; 457: 480-4.

18. Vael C, Desager $K$. The importance of the development of the intestinal microbiota in infancy. Curr Opin Pediatr 2009; 21: 794-800.

19. Simon TC, Gordon JI. Intestinal epithelial cell differentiation: new insights from mice, flies and nematodes. Curr Opin Genet Dev 1995; 5: 577-86.

20. Piazza AJ, Stoll BJ. Digestive system disorders. En: Nelson Textbook of Pediatrics. $18^{a}$ edición. RM Kliegman, HB Jenson, RE Behrman y BF Stanton, eds. Filadelfia: Saunders Elsevier. 2007; 753-56.

21. de la Cochetiere MF, Piloquet $H$, des Robert $C$, Darmaun $D$, Galmiche JP, Roze JC. Early intestinal bacterial colonization and necrotizing enterocolitis in premature infants: the putative role of Clostridium. Pediatr Res 2004; 56: 366-70.

22. Kanto WP Jr, Hunter JE, Stoll BJ. Recognition and medical management of necrotizing enterocolitis. Clin Perinatol 1994; 21: 335-46.

23. Hoyos $A B$. Reduced incidence of necrotizing enterocolitis associated with enteral administration of Lactobacillus acidophilus and Bifidobacterium infantis to neonates in an intensive care unit. Int J Infect Dis 1999; 3: 197-202.

24. Szajewska H, Setty M, Mrukowicz J, Guandalini. Probiotics in gastrointestinal diseases in children: hard and not-sohard evidence of efficacy. J Pediatr Gastroenterol Nutr. 2006; 42: 454-75.

25. Szajewska H, Guandalini S, Morelli L, Van Goudoever JB, Walker A. Effect of Bifidobacterium animalis subsp lactis supplementation in preterm infants: a systematic review of randomized controlled trials. J Pediatr Gastroenterol Nutr 2010; 51: 203-09.

26. Mohan R, Koebnick C, Schildt J, Mueller M, Radke M, Blaut M. Effects of Bifidobacterium lactis Bb12 supplementation on body weight, fecal pH, acetate, lactate, calprotectin, and IgA in preterm infants. Pediatr Res 2008; 64: 418-22.

27. Deshpande G, Rao S, Patole S. Probiotics for prevention of necrotising enterocolitis in preterm neonates with very low birthweight: a systematic review of randomised controlled 
trials. Lancet 2007; 369: 1614-20.

28. Deshpande G, Rao S, Patole S, Bulsara M. Updated metaanalysis of probiotics for preventing necrotizing enterocolitis in preterm neonates. Pediatrics 2010; 125: 921-30.

29. Deshpande G, Rao S, Patole S. Probiotics for preventing necrotizing enterocolitis in preterm neonates: a metaanalysis perspective. Functional Food Rev. 2011; 3: 22-30.

30. Deshpande G, Rao S, Keil AD, Patole S. Evidence-based guidelines for use of probiotics in preterm neonates. BMC Medicine 2011: 9: 92-104.

31. Bell MJ, Ternberg JL, Feigin RD, Keating JP, Marshall R, Barton L, Brotherton T. Neonatal necrotizing enterocolitis. Therapeutic decisions based upon clinical staging. Ann Surg.1978; 187: 1-7.

32. Wang $Q$, Jing $D$, Yimin Z. Probiotic supplement reduces risk of necrotizing enterocolitis and mortality I preterm very low-birth-weight infants: an updated meta-analysis of 20 randomized, controlled trials. J Pediatr Surg 2012; 47; 241-48.

33. Downard CD, Renaud E, St Peter SD, Abdullah F, Islam S, Saito JM, Blakely ML, Huang EY, Arca MJ, Cassidy L, Aspelund G; for the 2012 American Pediatric Surgical Association Outcomes Clinical Trials Committee. Treatment of necrotizing enterocolitis: an American Pediatric Surgical Association Outcomes and Clinical Trials Committee systematic review. J Pediatr Surg. 2012; 47: 2111-2122.

34. Taylor SN, Basile LA, Ebeling M, Wagner CL. Intestinal permeability in preterm infants by feeding type: mother's milk versus formula. Breastfeed Med. 2009; 4: 11-5.

35. Manzoni P. Use of Lactobacillus casei subspecies Rhamnosus GG and gastrointestinal colonization by Candida species in preterm neonates. J Pediatr Gastroenterol Nutr 2007; 45 Suppl 3: S190-94.

36. Ascher $S B$, Smith $P B$, Clark RH, Cohen-Wolkowiez M, Li JS, Watt K, Jacqz-Aigrain E, Kaguelidou F, Manzoni $P$, Benjamin DK Jr. Sepsis in young infants with congenital heart disease. Early Hum Dev 2012; 88 Suppl 2: S92-97.

37. Barraud D, Blard C, Hein F, Marçon O, Cravoisy A, Nace L, Alla F, Bollaert PE, Gibot S. Probiotics in the critically ill patient: a double blind, randomized, placebo-controlled trial. Intensive Care Med 2010; 36: 1540-47.

38. Besselink MG, van Santvoort HC, Renooij $W$, de Smet $M B$, Boermeester MA, Fischer K, Timmerman HM, Ahmed Ali $U$, Cirkel GA, Bollen TL, van Ramshorst B, Schaapherder $A F$, Witteman BJ, Ploeg RJ, van Goor $H$, van Laarhoven CJ, Tan AC, Brink MA, van der Harst E, Wahab PJ, van Eijck $\mathrm{CH}$, Dejong $\mathrm{CH}$, van Erpecum KJ, Akkermans LM, Gooszen HG; Dutch Acute Pancreatitis Study Group. Intestinal barrier dysfunction in a randomized trial of a specific probiotic composition in acute pancreatitis. Ann Surg 2009; 250: 712-9.

39. Cunningham-Rundles $S$, Ahrné $S$, Johann-Liang $R$, Abuav $R$, Dunn-Navarra AM, Grassey C, Bengmark S, Cervia JS. Effect of probiotic bacteria on microbial host defense, growth, and immune function in human immunodeficiency virus type-1 infection. Nutrients 2011; 3 : 1042-70.

40. Sullivan A, Nord CE. Probiotic lactobacilli and bacteraemia in Stockholm. Scand J Infect Dis 2006; 38: 327-31.

41. Jenke A, Ruf EM, Hoppe T, Heldmann M, Wirth S. Bifidobacterium septicaemia in an extremely low-birthweight infant under probiotic therapy. Arch Dis Child Fetal Neo- natal Ed 2012; 97: F217-18.

42. Snydman DR. The safety of probiotics. Clin Infect Dis 2008; 46 Suppl 2:S104-11.

43. Hempel S, Newberry S, Ruelaz A, Wang Z, Miles JN, Suttorp $M J$, Johnsen $B$, Shanman $R$, Slusser W, Fu N, Smith $A$, Roth B, Polak J, Motala A, Perry T, Shekelle PG. Safety of probiotics used to reduce risk and prevent or treat disease. Evid Rep Technol Assess (Full Rep) 2011; (200):1-645.

44. Theodorakopoulou M, Perros E, Giamarellos-Bourboulis EJ, Dimopoulos $G$. Controversies in the management of the critically ill: the role of probiotics. Int J Antimicrob Agents 2013; 42 Suppl: S41-44.

45. Ley RE, Turnbaugh PJ, Klein S, Gordon JI. Microbial ecology: human gut microbes associated with obesity. Nature 2006; 444: 1022-23.

46. Turnbaugh PJ, Ley RE, Mahowald MA, Magrini V, Mardis ER, Gordon JI. An obesity-associated gut microbiome with increased capacity for energy harvest. Nature 2006; 444: 1027-31.

47. Brignardello J, Morales P, Diaz E, Romero J, Brunser O, Gotteland M. Pilot study: alterations of intestinal microbiota in obese humans are not associated with colonic inflammation or disturbances of barrier function. Aliment Pharmacol Ther. 2010; 32: 1307-14.

48. Raoult D. Probiotics and obesity: a link? Nat Rev Microbiol 2009; 7: 616.

49. Delzenne $N$, Reid $G$. No causal link between obesity and probiotics. Nat Rev Microbiol 2009; 7: 901.

50. Ehrlich SD. Probiotics - little evidence for a link to obesity. Nat Rev Microbiol 2009; 7: 901.

51. Kondo S, Xiao JZ, Satoh T, Odamaki T, Takahashi S, Sugahara H, Yaeshima T, Iwatsuki K, Kamei A, Abe K. Antiobesity effects of Bifidobacterium breve strain $B-3$ supplementation in a mouse model with high-fat diet-induced obesity. Biosci Biotechnol Biochem 2010; 74: 1656-61.

52. Brunser O, Gotteland M, Cruchet S, Figueroa G, Garrido $D$, Steenhout $P$. Effect of a milk formula with prebiotics on the intestinal microbiota of infants after an antibiotic treatment. Pediatr Res. 2006; 59: 451-6.

53. Brunser O, Espinoza J, Araya M, Pacheco I, Cruchet S. Chronic iron intake and diarrhoeal disease in infants. A field study in a less-developed country. Eur J Clin Nutr. 1993; 47: 317-26.

54. Soofi S, Cousens S, Iqbal SP, Akhund T, Khan J, Ahmed I, Zaidi AK, Bhutta ZA. Effect of provision of daily zinc and iron with several micronutrients on growth and morbidity among young children in Pakistan: a cluster-randomised trial. Lancet 2013 Apr 17. doi:pii: S0140-6736(13)604377. $10.1016 /$ S0140-6736(13)60437-7.

55. Brunser O, Espinoza J, Araya M, Cruchet S, Gil A. Effect of dietary nucleotide supplementation on diarrhoeal disease in infants. Acta Paediatr. 1994 Feb;83(2):188-91.

56. Johansson ME, Ambort D, Pelaseyed T, Schütte A, Gustafsson $J K$, Ermund $A$, Subramani DB, Holmén-Larsson JM, Thomsson KA, Bergström JH, van der Post S, RodriguezPiñeiro AM, Sjövall H, Bäckström M, Hansson GC. Composition and functional role of the mucus layers in the intestine. Cell Mol Life Sci. 2011 Nov;68(22):3635-41.

57. Hammerman C, Bin-Nun A, Kaplan M. Safety of probiotics: comparison of two popular strains. BMJ. $2006 \mathrm{Nov}$ 11;333(7576):1006-8. 


\title{
Las posibilidades del empleo de lactobacilos en la gastroenterología y la nutrición humana
}

\author{
Therapeutic potential of the use of \\ lactobacilli in gastroenterology \\ and human nutrition
}

\begin{abstract}
Lactobacilli are normal inhabitants of the human intestine. They are also present in maternal milk, where Lactobacillus reuteri was first described. This confirms that maternal milk transfers components of the maternal microbiota to the offspring. L. reuteri ATCC 55730 decreases the intensity and duration of infantile colic defined as episodes of strident crying for at least 3 hours, 3 times a week during 3 months. Its etiology is unknown but recent evidence shows that affected infants harbor less lactobacilli and more Bacteroides in their feces. In 2008 it was shown that this strain carries plasmidia that could transfer resistance to antibiotics. For this reason $L$. reuteri it was cured of these factors and this resulted in L. reuteri DSM 17938 which is devoid of them; tests in vitro, in laboratory animals and in humans demonstrated that both strains are equivalent. The effect of $L$. reuteri in infantile colic may be explained by its blocking at the level of the dorsal ganglia of the spinal chord of the transmission to the central nervous system of afferent pain stimuli. L. reuteri has effects on gastroesophageal reflux probably through the acceleration of gastric emptying and it decreases the incidence and severity of necrotizing enterocolitis. Other positive effects are related to chronic constipation and acute diarrhea. L. reuteri synthesizes a molecule with intense bactericidal activity, $\beta$-hidroxy propenal o reuterin from glycerol, which may explain some of its effects. Lactobacillus rhamnosus GG ATCC 53103 is probably the probiotic that has been studied the most and for a longer period. It shortens the duration and it decreases the number of evacuations in acute diarrhea as well as the duration and frequency of vomiting. It also induces improvements of antibiotic associated diarrhea and of upper respiratory infections. The positive effects of Lactobacillus GG may be due to the stimulation of innate and adaptive immunity and to the activation of macrophages and of NK lymphocytes. One of its effects refers the response its administration induces in infants with atopy/eccema. Some studies have demonstrated that the severity and extent of the lesions is decreased after Lactobacillus GG administration, that may persist for some years after its administration has been ended. Lactobacillus GG also exerts positive effects on conditions such as the irritable bowel syndrome through mechanisms that are not known with certainty.

Key words: Lactobacillus reuteri ATCC 53730; Lactobacillus reuteri DSM 17938; Lactobacillus rhamnosus GG ATCC 53103; reuterin, acute diarrhea.
\end{abstract}

Esta revisión analiza la evidencia existente acerca de dos de los probióticos más estudiados y utilizados y su relación con diversos aspectos de la salud humana; estos son: Lactobacillus reuteri ATCC 55730 y la cepa que lo reemplazó, Lactobacillus
Oscar Brunser T.

Representante en Chile, Nestlé Nutrition Institute Santiago, Chile

Dirigir la correspondencia a:

Oscar Brunser.

Profesor de Pediatría, Universidad de Chile Avda. Las Condes 11287 - $5^{\circ}$ Piso - Las Condes Santiago - Chile

E-mail: oscar.brunser@CL.nestle.com

Este trabajo fue recibido el 9 de Julio de 2013 y aceptado para ser publicado el 27 de Agosto de 2013.

reuteri DSM 17938, y Lactobacillus rhamnosus GG. Para subrayar algunos aspectos funcionales que se estiman de interés se hará mención a algunas otras cepas de lactobacilos que poseen capacidades que abren otras posibilidades de manejo 
de problemas de salud.

\section{Lactobacillus reuteri ATCC 55730 y \\ Lactobacillus reuteri DSM 17938}

Lactobacillus reuteri y el cólico infantil. Lactobacillus reuteri fue descubierto en la leche de una madre peruana y clasificado erróneamente como una capa de L. fermentum. En 1980 fue identificado como una especie distinta y se le asignó el nombre de reuteri en recuerdo a su descubridor, Gerhardt Reuter (1). L. reuteri se caracteriza por sintetizar una molécula con estructura química simple a partir del glicerol, el $\beta$-propionaldehido, que recibió el nombre de reuterina y posee potente actividad antibacteriana para numerosos enteropatógenos pero que no alteraría la microbiota residente del intestino.

Una de las características más interesantes de $L$. reuteri es su efecto sobre el cólico del lactante. Este cuadro fue definido en 1955 por Wessel como episodios de Ilanto excesivo, estridente, que se presentan al menos 3 horas durante 3 días a la semana y a lo menos por 3 meses (2). Para su manejo se ha recurrido a tratamientos que van desde manipulaciones de la columna vertebral, infusiones de menta, manzanilla, jenjibre, eneldo o asafétida, masajes, camas vibratorias, fórmulas lácteas parcial o extensamente hidrolizadas, supresión de alimentos de la dieta materna e interrupción de la lactancia. Los tratamientos que han producido algunos efectos positivos son la administración de gotas de whisky (desechado porque interferiría con el desarrollo del sistema nervioso central) o el bromuro de cimetropio (anticolinérgico). Esta variedad de tratamientos indica que ninguno de ellos ha tenido efectos evidentemente positivos. En las culturas occidentales el cólico afecta a 10 a $20 \%$ de los lactantes entre el primer y el tercer año de vida (3). En un estudio efectuado en la Isla de Wright, Hide y cols. observaron que en la mayoría de los casos el cólico ya había desaparecido alrededor del $5^{\circ}$ mes de vida aunque en algunos casos se prolongó hasta el año de edad (4).

En 2004, Savino y colaboradores publicaron los resultados de un estudio de la microbiota fecal de lactantes con cólico. En los lactantes con cólico había disminuciones significativas de los recuentos de lactobacilos $(p<0,03)$ en comparación con los controles y una tendencia al aumento de los anaerobios ( $p$ $<0,06)$. Los autores no adelantaron explicaciones para estos cambios pero consideraron que de alguna manera jugarían un papel en la patogenia de la sintomatología (5). Posteriormente, en un estudio prospectivo, randomizado en el que el grupo control recibió simeticona, los investigadores evaluaron el efecto de L. reuteri ATCC 55730 sobre la duración del Ilanto en lactantes con cólico. Un total de 41 lactantes que recibieron L. reuteri ATCC 55730 completó el período de observación así como 42 controles. Al inicio del estudio, la duración del Ilanto fue comparable en ambos grupos (197 minutros (margen: 180 - 276) para el grupo que recibió el probiótico vs 197 minutos (margen 180-279) ( $p=0.987$ ) para el grupo qye recibió simeticona. Al cabo de una semana la duración había disminuido a 159 minutos en el grupo que recibió I. reuteri y fue 177 minutos en el grupo control. A los 28 días los valores fueron 59 minutos y 145 minutos, respectivamente. Al día 28 los autores consideraron que 39 de los 41 lactantes que recibieron L. reuteri habían respondido al tratamiento, en comparación con sólo 3 pacientes (7\%) en el grupo que recibió simeticona. El efecto de $L$. reuteri fue independiente de los antecedentes de familia, concluyendo que el probiótico ejerció un efecto favorable sobre la duración del cólico y que representaba una herramienta terapéutica eficaz (5). Sin embargo, no tuvieron una explicación para el período inicial de latencia de su efecto, de aproximadamente 7 días (6).

En 2008 un análisis del genoma de L. reuteri ATCC 55730 determinó que era portador en su ADN cromosómico de un gen para una beta-lactamasa pero que, adicionalmente, albergaba dos plasmidios que incluían genes de resistencia a la tetraciclina y la lincomicina. En consecuencia, la cepa original fue "curada" de sus plasmidios, generando una cepa hija que recibió la denominación de L. reuteri DSM 17938, sin capacidad de transferir esta resistencia a antibióticos a otras bacterias de la microbiota. Pruebas adicionales in vitro confirmaron que las características de la cepa original de $L$. reuteri, incluso aquellas que la caracterizaban como un probiótico, se mantenían en la nueva cepa (7). Con todo, se hizo necesario evaluar si los efectos de esta nueva cepa eran diferentes de los de la cepa original respecto del cólico infantil. Savino y colaboradores (10) compararon sus propiedades en un estudio en doble ciego, randomizado y controlado con placebo practicado en lactantes con cólico amamantados en forma exclusiva: un grupo de 25 lactantes recibió $L$. reuteri DSM 17938 y otros 21 recibieron el placebo. La bacteria fue administrada una vez al día en 5 gotas de una suspensión oleosa y proporcionaban 108 UFC del microorganismo. Se midió la duración diaria del llanto, que fue $370 \pm 120$ minutos vs $300 \pm 150$ minutos en el día $0(p=0,127) ; 95 \pm 85$ minutos vs $185 \pm 140$ minutos en el día $7(p=0,082) ; 60 \pm 70$ minutos vs $150 \pm 145$ minutos en el día 14 y $35 \pm 85$ minutos vs 90 \pm 148 en el día 21 para quienes recibieron el probiótico o la fórmula control, respectivamente (valores expresados como promedio \pm rango intercuartil). Además se observó que los lactantes que recibían el probiótico no sólo lloraban menos tiempo sino que respondían a la administración del probiótico en números significativamente más elevados que los controles al placebo. Al día 21 se observó un aumento de los recuentos de lactobacilos y de Escherichia coli y un descenso de C. butyricum en las heces de los niños que recibieron $L$. reuteri; en estos lactantes se produjo también una disminución del amoníaco fecal $(p<0,001)$. No hubo diferencias en la ganancia de peso o la frecuencia de episodios de regurgitación o en el número de evacuaciones. Los autores postularon que $L$. reuteri DSM 17938 tenía efectos positivos sobre el cólico e inducía cambios de la microbiota colónica que consideraron asociados con la mejoría clínica. Nuevamente se observó un período de latencia entre el inicio de la administración del probiótico y la mejoría del Ilanto. Szajewska y colaboradores publicaron recientemente un estudio en el que administraron el mismo agente y en la misma dosis a 40 niños con cólicos, a quienes compararon con igual número de lactantes que sirvieron de controles (11). Los resultados exitosos fueron significativamente más frecuentes en los lactantes del grupo experimental, en quienes la duración del llanto se acortó. Los padres de los lactantes del grupo que recibió $L$. reuteri DSM 17938 tuvieron la percepción de que la intensidad del cólico fue menor y que la calidad de vida del grupo familiar mejoró. Este estudio demostró nuevamente que al séptimo día el efecto positivo se vuelve evidente en cuanto a la proporción de lactantes que experimentan disminuciones de los episodios de llanto y su duración. Los autores postulan que el uso de L. reuteri DSM 17938 debería ser discutido rutinariamente con los padres, especialmente si se tiene en cuenta que no existe un tratamiento efectivo para el cólico infantil y que los probióticos tienen un perfil de inocuidad satisfactorio. El mecanismo que causa la disminución del cólico no se conoce con precisión pero existe evidencia de que puede estar asociado 
con modificaciones del funcionamiento de las vías nerviosas que conducen estímulos generados a nivel intestinal hacia los núcleos del sistema nervioso central encargados de la percepción del dolor. Rousseaux y colaboradores demostraron que la administración oral de Lactobacillus acidophilus NCFM a ratones estimulaba la expresión de receptores opioides $m$ y endocanabinoides en la pared intestinal de los animales. Utilizando un modelo de hipersensibilidad visceral en ratones, mostraron que la administración de este probiótico aumentaba en forma dosis-dependiente el umbral de dolor asociado con la distensión del colon, de manera comparable con lo producido por la administración de dosis farmacológicas de morfina (12). Demostraron asimismo que $L$. reuteri actúa sobre las neuronas de los ganglios dorsales de la médula espinal y sobre las terminaciones nerviosas intraabdominales del vago y en los núcleos encargados de la percepción del dolor a nivel del sistema nervios central (13-16). La forma en que las bacterias presentes en el lumen generan mecanismos que bloquean la transmisión en los ganglios dorsales de la médula no se conocen con precisión.

Indrio y colaboradores observaron que $L$. reuteri ATCC 55730 ejercía efectos sobre la motilidad del estómago al ser administrado a prematuros en una fórmula láctea e inducía aumentos significativos de la velocidad de vaciamiento gástriCo, asociados con disminuciones de las regurgitaciones (17). Este grupo evaluó el efecto de la administración de 108 UFC de L. reuteri DSM 17938 en 5 gotas de un vehículo oleoso una vez al día por 30 días en 42 lactantes de 3 a 12 meses de edad que satisfacían los Criterios de Roma III para la definición de regurgitación y cuyo incremento de peso y talla era normal; los controles fueron 21 lactantes que recibieron solamente la base oleosa. Los parámetros de vaciamiento gástrico fueron determinados por ultrasonido después de ingerir la fórmula y se calculó la sección transversal del antro gástric: la disminución de este parámetro fue utilizada como un marcador del vaciamiento. Al final de la intervención el área del antro gástrico en ayunas fue significativamente menor en los lactantes que recibieron el $L$. reuteri y en elloa la velocidad de vaciamiento gástrico aumentó significativamente en comparación con los controles ( $p<0,01$ para ambas mediciones). El número diario de episodios de regurgitación se correlacionó con la disminución de la sección transversal del antro $(p=0.004)$. La comparación del grupo que recibió el lactobacilo con el grupo que recibió el placebo permitió demostrar una aceleración del vaciamiento gástrico, proponiendo que L. reuteri DSM 17938 modificaría el funcionamiento de las células intersticiales de Cajal y/o de las fibras musculares lisas gástricas (17).

\section{Otros efectos de L. reuteri ATCC 55730, DSM 17938}

y de otras cepas de lactobacilos

L. reuteri DSM 17938 fue utilizado en la prevención de la enterocolitis necrosante ECN en prematuros $\leq 1000 \mathrm{~g}$ de peso nacidos en Estados Unidos entre enero de 2004 y junio de 2009 en comparación con prematuros con características similares nacidos entre julio de 2009 y abril de 2011. En el primer grupo se evaluaron 232 prematuros y 79 en el segundo. La incidencia de ECN fue significativamente más baja en el grupo tratado con L. reuteri DSM 17938 (2/79; 2,5\% vs el grupo no tratado $(35 / 232 ; 15,1 \%)$. No hubo diferencias entre los grupos en relación con infecciones tardías por bacterias Gram-negativas o por hongos. De acuerdo con estos resultados es posible calcular que la administración de $L$. reuteri DSM 17938 previene 1 caso de ECN por cada 8 prematuros que recibieron preventivamente el probiótico (18).
L. reuteri DSM 17938 fue evaluado por Coccurullo y colaboradores en 44 lactantes con constipación crónica (19). Su edad promedio era 8,2 meses al ingresar al protocolo y de ellos 22 recibieron en 5 gotas/día de solución oleosa que proporcionaban $10^{8}$ UFC; al igual que en el estudio de Indrio (17) los controles sólo recibieron el vehículo. La constipación funcional fue definida de acuerdo con los criterios de Roma III (2 o menos evacuaciones/semana, pujos intensos, antecedentes de retención fecal excesiva con bolo fecal duro de gran diámetro y expulsión probablemente dolorosa, con presencia frecuente de una masa fecal en el recto). Durante el desarrollo del estudio la frecuencia semanal de evacuaciones aumentó progresivamente a las 2, 4 y 8 semanas en quienes recibieron el probiótico en comparación con el grupo que recibió el placebo. La consistencia fecal fue disminuyendo, aunque este último parámetro no fue diferente del grupo control; tampoco hubo diferencias respecto del llanto al defecar. Los autores estiman que este probiótico representaría una opción atractiva para el manejo de la constipación crónica de los lactantes. La administración de L. reuteri DSM 17938 estaría asociada con modificaciones de la motilidad del tubo digestivo, lo que para los autores probablemente se relacionaría con cambios funcionales de las células de Cajal. El probiótico actuaría mediante moléculas que actúan como mensajeros en los plexos nerviosos o indirectamente a través de mecanismos que modifican el funcionamiento de las células dendríticas. Probablemente los mecanismos que actúan sobre los plexos nerviosos de la pared intestinal explican también el efecto favorable de L. reuteri DSM 17938 en el dolor abdominal funcional en preescolares y escolares, en quienes se observaron disminuciones significativas de su intensidad aunque sin modificaciones de la frecuencia de los episodios. El efecto sobre la intensidad del dolor se prolongó en el tiempo después de interrumpir el probiótico (20) y el mecanismo podría ser similar al propuesto por Rousseaux (12) y por Storr y cols. (21). El efecto de L. reuteri DSM 17938 en el tratamiento de la diarrea aguda ha sido estudiado por diferentes grupos de investigadores. Según Wanke y Szajewska (22), L. reuteri DSM 17938 en una dosis de 108 UFC por día no previno la diarrea intrahospitalaria en niños de 1 a 48 meses de edad, incluyendo aquella causada por el rotavirus. Tampoco observaron efectos sobre manifestaciones secundarias tales como la aparición de nuevos episodios de diarrea, modificaciones de su duración o recurrencias después de 48 horas de evacuaciones normales; tampoco hubo modificaciones en riesgo de evoluciones a la cronicidad o la necesidad de rehidratación. Sin embargo, este estudio tiene algunos problemas de diseño. En el primero de estos estudios se estudió el efecto de L. reuteri DSM 17938 en la prevención de la diarrea nosocomial (22). Este es un cuadro conocido con diferentes denominaciones (infecciones asociadas con los procesos de cuidado de la salud, infecciones adquiridas en el hospital o de comienzo intrahospitalario) que se inicia 48 horas después de la admisión, cuya etiología más frecuente es el rotavirus y afecta al $27 \%$ de los niños hospitalizados. Su prevalencia exacta se desconoce porque es difícil obtener información de calidad al respecto. Se considera que L. rhamnosus GG y Bifidobacterium lactis ejercen efectos protectores, propiedad que también puede ejercer L. thermophilus (6-8). El estudio de Wanke y Szajewska fue prospectivo, randomizado, en doble ciego y controlado con placebo fue llevado a cabo en Varsovia, Polonia, entre 2009 y 2011 en niños de 1 a 48 meses de edad hospitalizados y cuyos diagnósticos excluían la diarrea aguda. Los criterios de exclusión fueron un episodio previo de diarrea en los 3 días 
anteriores a la admisión, cualquier otro síntoma sugerente de gastroenteritis, la presencia de sangre en las deposiciones y la alimentación con leche materna. L. reuteri DSM 17938 fue administrado en un dosis diaria única de 108 unidades formadoras de colonia (UFC) en 5 gotas de solución oleosa que fueron administradas bajo la supervisión de personal del estudio.

El principal resultado fue la incidencia de diarrea nosocomial, definida como $\geq 3$ deposiciones líquidas en 24 horas detectadas 72 horas después del ingreso al hospital. Los resultados secundarios fueron la detección de antígenos de rotavirus en las deposiciones, la incidencia de diarrea y su duración, la recurrencia de la sintomatología y la evolución prolongada (mayor de 14 días). Las muestras de deposiciones obtenidas al ingreso de cada uno de los niños fueron examinadas para detectar antígenos de rotavirus e identificar bacterias mediante métodos corrientes de cultivo. No parece que se hayan obtenido contemporáneamente muestras de los niños asintomáticos participantes durante la durante su hospitalización. De acuerdo con la literatura se podía esperar que 33\% de los niños desarrollaran un episodio de diarrea durante su hospitalización. Para obtener un resultado clínicamente significativo se estipuló que se esperaba una disminución de los episodios de diarrea de 50\% respecto del grupo placebo. Se calculó asimismo que el tamaño mínimo de la muestra debía ser de 88 pacientes y se adicionó un porcentaje de $20 \%$ para cubrir la deserción (dropout), con lo que el tamaño total de la muestra llegó a 106 sujetos, con 53 en cada grupo.

Al llevar a cabo la distribución de los participantes 54 niños conformaron el grupo que recibió el probiótico y 52 en el grupo que recibió el placebo. Las características demográficas de ambos grupos fueron comparables. Los resultados del estudio están resumidos en la tabla 1. Este estudio tiene como ventajas metodológicas el diseño experimental en doble ciego y controlado por placebo, el seguimiento durante toda la hospitalización y la obtención de una muestra de deposiciones en el momento de la hospitalización (muestra basal). Otra ventaja es que se consideró como episodios de origen nosocomial sólo a aquellos que fueron detectados después de 72 horas de la admisión en vez de las 48 horas aceptadas rutinariamente. La ausencia de diferencias en la incidencia de diarrea se mantuvo tanto si el intervalo inicial fue considerado de 48 o 72 horas. El efecto de la administración de antibióticos no fue tomado en consideración ya que el tratamiento de la diarrea es el mismo cualquiera sea su etiología y no debería incluir antibióticos. Por esta razón no se buscó específicamente la presencia de Clostridium difficile. La carencia de efecto de $L$. reuteri DSM 17938 fue atribuida por los autores a aspectos relacionados con el probiótico. En primer lugar, a la posibilidad de que este no sea el agente indicado para la prevención de esta patología, ya que el que resulte activo en el cólico no significa que necesariamente tenga que ser activo en procesos de diarrea. En segundo lugar, la dosis del probiótico puede haber sido insuficiente, aunque es la recomendada por el fabricante. Las dosis óptimas no han sido establecidas y es posible que una dosis más elevada tenga efectos positivos; es importante y asimismo probable que los resultados de la dosis de un probiótico no sea equivalente a la dosis activa de otro u otros microorganismos. Por ejemplo, en un estudio en el que L. rhamnosus GG mostró tener eficacia en la prevención de diarrea la dosis empleada fue de $10^{10}$ microorganismos al día (22).

Con todo, este estudio tiene problemas de diseño. En primer lugar, el rango de edad incluye lactantes menores y preescolares. Es un hecho conocido que después de los 2 años de edad, y sobre todo después de los 3 años de edad, la incidencia de diarrea disminuye porque la calidad de las respuestas del sistema inmune innato y adaptativo mejoran conjuntamente con el establecimiento de una microbiota residente más parecida a la de los adultos. De manera que un diseño más adecuado debería haber dividido y evaluado a la población en menores y mayores de 24 y/o 36 meses. En este nuevo diseño propuesto, el principal inconveniente es que queda estratificado por edad, por lo que para obtener un número adecuado de participantes que permitiría un análisis estadístico más preciso, habría sido necesario aumentar el número de sujetos participantes en cada uno de los grupos a más del doble. Una segunda objeción sería que los autores no parecen haber analizado la influencia de la duración de la hospitalización en la incidencia de diarrea. Mientras más prolongada es la hospitalización mayor es el riesgo de desarrollar episodios de esta enfermedad; por lo tanto, para determinar si L. reuteri DSM17938 ejerce efectos protectores habría sido

\section{TABLA 1}

Resultados primario y secundarios de L. reuteri DSM 17938 en la diarrea nosocomial.

\begin{tabular}{|c|c|c|c|c|}
\hline $\begin{array}{l}\text { Resultado } \\
(n=54)\end{array}$ & $\begin{array}{l}\text { Probiótico } \\
(\mathrm{n}=52)\end{array}$ & Placebo & RR (IC 95\%) & $\begin{array}{c}\text { Diferencia } \\
\text { promedio (IC 95\%) }\end{array}$ \\
\hline \multicolumn{5}{|l|}{ Primario n (\%) } \\
\hline Diarrea nosocomial & $18(33)$ & $16(31)$ & $1,06(0,7-1,5)$ & \\
\hline \multicolumn{5}{|l|}{ Secundarios } \\
\hline Rotavirus n(\%) & $10(18)$ & $9(17)$ & $1,04(0,6-1,6)$ & \\
\hline \multicolumn{5}{|l|}{ Diarrea n (\%) } \\
\hline \multicolumn{5}{|l|}{ Días con diarrea } \\
\hline Días \pm DS & $3,9 \pm 1,1$ & $4,1 \pm 1,1$ & & $0,2(-0,6$ a 0,2$)$ \\
\hline Diarrea recurrente & --- & --- & & \\
\hline Diarrea crónica & --- & --- & & \\
\hline Rehidratados & $6(11)$ & $19(19)$ & $0,7(0,3-1,2)$ & \\
\hline Duración de la hospitalización & $7,7 \pm 27$ & $7,3 \pm 2,7$ & & $0,41(-0,65$ a 1,45$)$ \\
\hline
\end{tabular}


interesante estratificar a los pacientes de acuerdo con la duración de su estadía en el hospital. Por este motivo, resultan más apropiados los seguimientos por períodos prolongados, como sucedió en el estudio de Saavedra y colaboradores, que demostró que L. rhamnosus GG protegía de la diarrea aguda (23). Otro factor que puede modular la calidad de los resultados es que L. reuteri DSM 17938 puede ejercer sus efectos protectores con una cierta latencia y que, por lo tanto, en el estudio en discusión haya habido participantes en quienes duración de la hospitalización no llegó a ser suficiente como para poner en evidencia los efectos protectores o estos fueron menores, especialmente si se tiene en cuenta la velocidad con que se instalan las respuestas inmunes adaptativas. Este es un aspecto importante si se considera que la duración promedio del período de hospitalización fue 7,7 $\pm 2,7$ días y 7,3 $\pm 2,7$ días en los grupos "Probiótico" y "Placebo", respectivamente (22).

Francavilla y colaboradores observaron que $L$. reuteri DSM 17938, administrado como adjunto a la rehidratación de lactantes en una dosis de 4 × 108 UFC/día disminuyó la duración de la diarrea en aproximadamente un día, con mayor impacto en el segundo y tercer días de su administración y redujo la frecuencia de recaídas (24). Estos resultados coinciden con los obtenidos por Shornikova en Estonia (25); es posible que el efecto positivo sobre la diarrea aguda sea explicado por mecanismos, propios de este probiótico, entre ellos la capacidad de sintetizar reuterina (26). L. reuteri DSM 17938 ha demostrado ser efectivo en la prevención de la diarrea que se presenta en el curso del tratamiento con antibióticos para erradicar el $H$. pylori (27).

Los antecedentes antes mencionados apoyan la idea que desde el punto de vista funcional $L$. reuteri, ATCC 55730 y $L$. reuteri DSM 17938, funcionan de manera equivalente en las patologías estudiadas. Es importante tener en cuenta estos hallazgos ya que otras cepas de la misma especie microbiana poseen efectos totalmente diferentes. Por ejemplo, Lactobacillus reuteri NCIMB 30242 hace descender los niveles de colesterol sérico de adultos hipercolesterolémicos porque posee actividad de hidrolasa de las sales biliares. (28-32). Nuevamente este sería un efecto cepa-específico.

Existe una amplia bibliografía respecto del efecto de $L$. reuteri en la diarrea aguda. Los resultados con varias cepas de $L$. reuteri en la diarrea aguda son variables; algunas publicaciones indican que es efectivo en el control de esta enfermedad mientras que según otros no tendría efecto. En 1997 Shornikova y cols. publicaron estudios que demostraron que $L$. reuteri acorta la duración de la diarrea en forma dosis-dependiente, de manera que su duración fue 2,5 \pm 1,5 días en el grupo que recibió placebo ( 25 niños), 1,9 0,9 días en quienes recibieron $10^{7}$ UFC una vez al día por 5 días (20 niños) y 1,5 $\pm 1,1$ días en quienes recibieron $10^{10}$ UFC por igual período de tiempo (33). Los coprocultivos demostraron que se alcanzó un nivel satisfactorio de colonización del tracto gastrointestinal, con recuentos de $4,5 \pm 2,0 \log 10 \mathrm{UFC} / \mathrm{g}$ en quienes recibieron los recuentos bajos de L. reuteri y 6,1 $\pm 1,2 \log 10 \mathrm{UFC/g}$ en quienes recibieron la dosis más elevada y de sólo $2,8 \pm 1,6$ log10 UFC/g en los que sirvieron de controles, . De los pacientes incorporados a estos estudios, 75\% estaba afectado por rotavirus en el primer estudio mientras que estaba presente en todos los del segundo estudio (33).

Publicaciones posteriores, algunas de ellas efectuadas con L. reuteri ATCC 55730 y otras con la cepa DSM 17938, demostraron efectos beneficiosos de mayor o menor intensidad en episodios de diarrea de diversa etiología, principalmente en aquella causada por rotavirus (34-37). L. reuteri ATCC 55730 ejerció efectos preventivos sobre la diarrea en pacientes colonizados por H. pylori y tratados con levofloxacino; al mismo tiempo la tasa de erradicación aumentó significativamente ( $p$ $<0,05)(38)$. En el estudio de Wanke y Szajewska (39) en el que indicaron que L. reuteri DSM 17938 no previno la aparición de episodios de diarrea intrahospitalaria, se ensayó una dosis diaria de L reuteri DSM 17938 (10 UFC) pero no se puede descartar que dosis más altas ejerzan efectos preventivos. Contrastando con este resultado, otros tres estudios demostraron que Lactobacillus GG ejerce efectos preventivos en la diarrea intrahospitalaria (42) al igual que dos cepas diferentes de $L$. rhamnosus, 19070 y DSM 12246 (40, 41). Estos resultados refuerzan el concepto, expresado anteriormente, que los efectos de los probióticos tienen especificidad respecto de especie y cepa y que otro aspecto importante es la utilización de dosis óptimas.

En marzo de 2012 L. reuteri DSM 17938 recibió la calificación GRAS de parte de la Food and Drug Administration (FDA) de los Estados Unidos.

\section{Lactobacillus rhamnosus GG (ATCC 53103)}

Lactobacillus GG es una cepa aislada en 1983 del tracto gastrointestinal de un individuo sano; fue descrita por Gorbach y Goldin (de cuyas iniciales se originó la denominación) y fue patentada en 1985 (42). Está cepa está registrada en la American Type Cell Collection (ATCC) con el número 53103. Lactobacillus GG fue clasificado originalmente como L. acidophilus, posteriormente como $L$. casei y finalmente como $L$. rhamnosus cuando se describió la totalidad su genoma. Goldin y colaboradores demostraron que Lactobacillus GG sobrevivía el paso a lo largo del tubo digestivo (42), persistía por 4 días en las heces de $87 \%$ de los voluntarios que lo habían ingerido y era detectable en $33 \%$ de ellos hasta los 7 días; además inducía descensos de la $\beta$-glucuronidasa fecal (42). Resultados similares en cuanto a su persistencia de en el intestino humano fueron observados (43-45).

Lactobacillus GG en la diarrea aguda. En 1995 Majamaa y colaboradores observaron que la administración de Lactobacillus GG acortaba en niños en casi 24 horas la duración de la diarrea asociada con la presencia de rotavirus $(1,8 \pm 0,8$ días) en comparación con lo observado cuando se administró L. casei ( $2,8 \pm 1,2$ días) y 2,6 1,2 días cuando se administró una mezcla de Streptococcus thermophilus y L. delbrückii subsp bulgaricus como control. Estos resultados se asociaron con aumentos de IgA secretoria específica para rotavirus en las heces y en el suero de los convalecientes (46). Estudios posteriores confirmaron estos resultados en la diarrea por rotavirus aunque el efecto sobre la diarrea de etiología bacteriana es variable (47-53).

Un estudio efectuado en Kolcatta, India, en menores de 36 meses con diarrea definida como > 3 evacuaciones diarias no reveló diferencias en su evolución clínica entre quienes recibieron Lactobacillus GG y el grupo control (microcelulosa), excepto en que en el grupo que recibió el probiótico se observó una disminución de los vómitos. Sin embargo, aunque el número de niños estudiados por protocolo en este estudio es bastante grande (105 niños por grupo), ambos grupos eran heterogéneos en cuanto a su alimentación, que fueron amamantados exclusiva o parcial o alimentados con fórmulas y además presentaban grados variables de desnutrición, principalmente moderada, con una alta proporción de síntomas de malabsorción de lactosa. Los lactantes con diarrea por rotavirus recuperaron su estado nutricional previo al episodio de diarrea con mayor lentitud (54). 
Dos estudios australianos comunicaron no haber observado efectos positivos de Lactobacillus GG sobre la evolución de la diarrea. El primero (58) fue llevado a cabo en adultos gravemente enfermos que recibían alimentación por sonda gástrica y recibieron dos veces al día una preparación (Floratil, Conagra, USA) que contenía $10^{10}$ UFC de Lactobacillus GG y $280 \mathrm{mg}$ de inulina en una cápsula de gelatina. En el diseño en doble ciego el grupo control recibía la cápsula con inulina sin el probiótico (55). No se observaron diferencias significativas entre ambos grupos en cuanto a la duración o la intensidad de la diarrea; incluso hubo cierta tendencia a una mayor duración de los episodios y del número de evacuaciones en el grupo experimental, pero sin llegar a tener significancia estadística. Sin embargo, este estudio origina objeciones acerca de su diseño por la gravedad de los pacientes, el intenso compromiso del estado nutricional de algunos de ellos, el tratamiento simultáneo de C. diffícile con metronidazol, el uso de aspartato de magnesio y de una fórmula alimenticia con alta osmolaridad. Además, no se efectuaron estudios para aclarar la intervención de agentes virales o bacterianos en la etiología de la diarrea. En el segundo estudio, Ritchie y colaboradores (56) controlaron clínicamente a niños aborígenes australianos de 4 meses a 2 años de edad que presentaban diarrea y a quienes, en un estudio en doble ciego, randomizado y con grupo control, se les administró disuelto en agua destilada 3 veces al día el contenido de cápsulas con $5 \times 10^{9}$ UFC de Lactobacillus GG o un placebo con igual apariencia. Los niños recibieron además hidratación oral o parenteral de acuerdo con su estado clínico, $20 \mathrm{mg}$ de zinc y una dosis única de 50.000 o 100.000 unidades de vitamina A. La presencia de malabsorción intestinal fue evaluada mediante la medición de ${ }^{13} \mathrm{CO} 2$ en el aire espirado después de administrar ${ }^{13} \mathrm{C}$-sacarosa. De los participantes, cuya edad promedio era 9 meses aproximadamente, el $70 \%$ estaba amamantado. En algunos pacientes los episodios de diarrea estaban asociados con la presencia de rotavirus, enteropatógenos o parásitos (54 \% en el grupo experimental y 38 $\%$ en el grupo control) y algunos presentaban comorbilidades (pioderma, neumopatías, infecciones del tracto urinario u otitis). No se detectaron diferencias significativas en la excreción de ${ }^{13} \mathrm{CO} 2$ durante los días primero y cuarto aunque hubo cierto grado, no significativo, de mejoría de estos valores. Los probióticos no disminuyeron la duración de la diarrea pero el grupo que recibió el probiótico tuvo menos evacuaciones durante el día 2 del tratamiento, diferencia que desapareció en los días siguientes (56). Como el estudio anterior (55), este estudio tiene problemas de diseño tales como tamaño muestral inadecuado, heterogeneidad clínica de los pacientes y la administración de zinc y vitamina $A$, que pueden haber interferido con las respuestas a los probióticos (56). En cuanto a la función intestinal, en vez de la prueba con $1{ }^{3} \mathrm{C}$-sacarosa hubiera sido preferible realizar mediciones de la permeabilidad del tubo digestivo (sacarosa, lactulosa/manitol o sucralosa).

Un tercer estudio realizado en Perú tampoco demostró efectos clínicos positivos en la evolución de la diarrea asociados con la administración de Lactobacillus GG aguda (57). Este estudio adolece de cuatro problemas: los niños admitidos al grupo que recibió Lactobacillus GG probablemente eran casos más graves ya que en un mayor porcentaje (60 \%) sufría de deshidratación más intensa en comparación con el grupo control (40\%). La administración del probiótico fue tardía ya que para obtener efecto se aconseja su administración precoz; la prevalencia de casos de diarrea por rotavirus fue más elevada en el grupo control (39\% vs $24 \%$; $p<0,05$ ). Finalmente, casi la mitad de ambos grupos evidenció durante el estudio síntomas y signos de fermentación intestinal (evidenciada por el descenso del pH fecal), lo que es un índice de agravamiento del daño de la mucosa intestinal con aparición de intolerancia a los hidratos de carbono y especialmente, a la lactosa de la fórmula usada para alimentarlos (57).

Diversos autores sostienen con mayor o menor énfasis que Lactobacillus GG protege de la diarrea aguda, incluyendo de aquella nosocomial. Guandalini mantiene que muchos estudios "...muestran consistentemente un beneficio estadísticamente significativo y beneficios clínicos moderados con el uso de unas pocas cepas de probióticos claramente identificados principalmente Lactobacillus GG y Saccharomyces boulardii pero también $L$. reuteri- en el tratamiento de la diarrea líquida, primariamente en aquella causada por rotavirus, en lactantes y preescolares de países desarrollados" (58). Szajewska y colaboradores mostraron en un meta-análisis que Lactobacillus GG disminuye significativamente la duración de la diarrea aguda, especialmente de aquella causada por rotavirus y en menor grado en los casos sin etiología demostrada sin afectar, sin embargo, el número de evacuaciones emitidas. El probiótico también disminuye los vómitos en el segundo día del tratamiento y la duración de las hospitalizaciones. Szajewska y colaboradores concluyen que el uso de Lactobacillus GG está asociado con beneficios clínicos en el tratamiento de la diarrea aguda en niños de los países desarrollados (49). PiescikLech y colaboradores mostraron que la adición de smectita al tratamiento de la diarrea aguda con solución de rehidratacion oral + Lactobacillus GG no aumentaba su eficiencia. Sin embargo, pese al resultado positivo para Lactobacillus GG, en este estudio faltan dos controles: un grupo que debería recibir solamente smectita y otro que no debería recibir ningún tratamiento adicional, excepto rehidratación y alimentación $y$, sólo si fuese pertinente, antibióticos. El problema con este nuevo diseño propuesto es que para alcanzar una potencia estadística adecuada el número de pacientes que se requiere enrolar se multiplica exponencialmente (59).

Lactobacillus rhamnosus GG y diarrea asociada con el uso de antibióticos. Lactobacillus rhamnosus GG es efectivo en el tratamiento de la diarrea asociada con los tratamientos con antibióticos. Estos resultados son respaldados por varias publicaciones que apoyan la idea de que este probiótico debería ser la primera elección en el tratamiento de este cuadro y que incluso tendría efectos preventivos (59-63).

Lactobacillus rhamnosus GG en infecciones respiratorias. Una de las causas frecuentes de ausentismo a los jardines infantiles son las infecciones respiratorias, que afectan $2-3$ veces más a estos niños que a aquellos que permanecen en su hogar. El mayor número de episodios resulta en aumentos de los gastos no sólo para el sistema educacional sino porque intervienen otros factores tales como el ausentismo materno al trabajo, consultas al sistema de salud, adquisición de medicinas, entre otras (64).

Hattaka y colaboradores evaluaron el efecto de la administración de una fórmula láctea con Lactobacillus GG sobre el número de días con síntomas respiratorios y gastrointestinales en 571 niños de 1 a 6 años de edad que concurrían a 18 guarderías infantiles de Helsinki, Finlandia. Los niños que recibieron el probiótico tuvieron menos días de ausencia durante los 7 meses de observación y una disminución del $17 \%$ de las infecciones respiratorias y sus complicaciones junto con un $19 \%$ de descenso del uso de antibióticos (65).

Recientemente fueron publicados dos estudios acerca de los efectos de Lactobacillus GG en infecciones respiratorias en niños que concurrían a guarderías infantiles o estaban 
hospitalizados en Zagreb, Croacia. En ambos casos los niños recibieron $100 \mathrm{ml}$ de una fórmula que contenía $10^{9}$ UFC de Lactobacillus GG o, la misma fórmula sin este agente como control. Los niños que concurrían a jardines infantiles recibieron este producto durante 3 meses; aquellos hospitalizados la recibieron mientras duró su estadía en el hospital. En los jardines infantiles se observó una disminución significativa del riesgo de infecciones respiratorias [RR 0,63; CI 95\% 051 - 0,79; número necesario para tratar 5 (rango 3-8 días)]; no se detectaron efectos preventivos sobre las infecciones gastrointestinales. La frecuencia de episodios de diarrea con duraciones mayores de 3 días de los fue menor en quienes recibieron Lactobacillus GG pero no hubo diferencias respecto de la incidencia de infecciones broncopulmonares. Tampoco hubo diferencias en la incidencia de vómitos o diarrea al comparar los niños del grupo experimental con sus controles. En los niños que recibieron el placebo, el número de días con síntomas respiratorios fue mayor $(p<0,001)$ y su riesgo de infecciones del tracto respiratorio fue 2,88 veces mayor en comparación con quienes recibieron Lactobacillus GG. En los niños hospitalizados los resultados fueron comparables pero con algunas diferencias ya que sufrieron menos infecciones gastrointestinales y del tracto respiratorio, menos episodios de diarrea y de menor duración, aunque la duración de las hospitalizaciones no se modificó. Los autores manifiestan que Lactobacillus GG puede ser útil para disminuir el riesgo de enfermedades respiratorias en los niños que concurren a guarderías infantiles o en quienes están expuestos al riesgo de infecciones nosocomiales $(66,67)$.

Otra publicación evaluó la sintomatología respiratoria de niños de 2 a 6 años de edad que concurrían a guarderías infantiles en Finlandia y confirma que en quienes completaron un seguimiento de 28 semanas se observó una disminución del número de días con al menos un síntoma respiratorio (Lactobacillus GG: 4,71 días/mes (CI $95 \%$ 4,52 -4,90) vs 5,67 días/ mes en el grupo placebo (IRR 0,83: IC $95 \% 0,78-0,88$ : $p<$ $0,01)(68)$. Otras publicaciones también muestran resultados que concuerdan con la información precedente.

Respecto de los mecanismos que explicarían los efectos positivos de Lactobacillus GG se puede especular que estos resultados extradigestivos se deberían a la estimulación de la inmunidad tanto innata como adquirida, y a linfocitos B y $\mathrm{T}$ que migran desde el tubo digestivo y se localizan en el aparato respiratorio produciendo IgA específica e IgG a nivel local. En estudios in vitro se ha demostrado que Lactobacillus GG activa macrófagos y células natural killer además de procesos antiinflamatorios y de reparación. Por otra parte, LactobacillusGG sintetiza p40, una proteína soluble que mediante la síntesis del receptor para el factor de crecimiento epitelial (EGFR, epithelial growth factor receptor) previene la apoptosis de las células epiteliales intestinales inducida por citoquinas. En modelos animales la proteína p40 previene las alteraciones de la función de barrera del epitelio intestinal $(69,70)$.

Lactobacillus GG y manifestaciones de alergia, eccema y atopia. Uno de los fenómenos más notables observados en los decenios recientes es el aumento de las manifestaciones alérgicas en todas sus formas y ámbitos geográficos (7174). Este fenómeno se observa también en Chile, aunque las cifras de que se dispone son menos precisas. Las causas de este aumento no se conocen una de las explicaciones se fundamenta en los postulados de la hipótesis de la higiene (75). Aproximadamente $10 \%$ de la población menor de 10 años puede estar afectada por fenómenos de tipo alérgico $(76,77)$. Como se demostró que los probióticos modulaban el funcionamiento del sistema inmune, que está en desarrollo durante la gestación e incluso después del parto, algunas de las primeras investigaciones en este campo exploraron este enfoque. Kalliomäki e Isolauri (78) presentaron evidencia de este efecto de los probióticos, que podría ser explicado por disminuciones de los fenómenos inflamatorios en la mucosa intestinal con reforzamiento de la función de barrera. Una serie de tres artículos describieron el seguimiento por varios años de una cohorte de niños finlandeses cuyas sus madres tenían antecedentes de atopia al igual que otros componentes del grupo familiar. Las madres recibieron una cápsula que contenía $1 \times 10^{9}$ UFC de Lactobacillus GG o un placebo con igual aspecto dos veces al día en las 2 a 4 semanas previas al parto. Después del parto las madres que amamantaban podían seguir ingiriendo el probiótico pero si no amamantaban el lactante recibía el contenido de las cápsulas disuelto en agua; en ambos casos los recuentos de Lactobacillus GG en las heces de los lactantes fueron similares. Los niños fueron examinados a los $3,6,12,18$ y 24 meses, esta última en la que se evaluaron los resultados del tratamiento. La evolución de las manifestaciones cutáneas de atopia, principalmente el eccema, se efectuó mediante el índice SCORAD. Se practicó a los niños un prick test cutáneo a los 6, 12 y 24 meses además de mediciones de la IgE total y específica para la leche de vaca en la sangre del cordón umbilical y a los 3, 12 y 24 meses. Al nacer los lactantes de ambos grupos fueron comparables en sus características antropométricas y de laboratorio. A los 2 años 46/132 niños (35\%) tenían manifestaciones de eccema y 6 eran asmáticos. Se les practicó prick tests para diversos alérgenos, los que resultaron positivos con más frecuencia en los niños con eccema. En los niños que recibieron el probiótico, la frecuencia de eccema atópico fue la mitad que en los niños del grupo control, aunque la extensión de las lesiones era semejante. El efecto preventivo era independiente de la forma en que el Lactobacillus GG fue administrado. Las concentraciones de IgE total y los aumentos de IgE específica fueron comparables en ambos grupos. Los autores postularon que la microbiota intestinal jugaría un papel importante en modulación de la inmunidad tanto a nivel intestinal como sistémico y que los probióticos podrían participar en este mecanismo, lo que en el caso de Lactobacillus GG se manifestaría por la disminución de la atopia cutánea. Estos pacientes fueron evaluados a los 4 y 7 años de evolución del estudio por los mismos autores $(79,80)$. A los 4 años se diagnosticó eccema en 14/53 niños que habían recibido Lactobacillus GG en contraste con 25/54 en el grupo control (RR 0,57; IC $95 \%$ : 0,33-0,97). No hubo diferencias significativas en los demás parámetros estudiados (óxido nitroso en el aire espirado, prick tests, mediciones de IgE) (82). A los 7 años, los resultados expresados como curvas de Kaplan-Meier en que se comparó la presencia de fenómenos de atopia demostraron que el riesgo acumulado de desarrollar eccema era menor en el grupo tratado con Lactobacillus GG (42\% vs 66,1\%; RR 0,64; IC $95 \%$ 0,45 - 0, 92); el análisis de regresión de Cox demostró que el riesgo de desarrollar eccema también era significativamente menor en quienes recibieron el probiótico [relación de probabilidad (odds ratio) 0,58; IC $95 \% 0,35-0,94 ; p=0,027]$. Los autores no proporcionaron una explicación para estos resultados ya que los otros parámetros estudiados en esta cohorte son comparables en ambos grupos. Se sabe que en los niños con eccema hay aumentos del transporte de antígenos a través del epitelio intestinal y que hay alteraciones de la microbiota intestinal residente, pero la importancia relativa de estos factores es desconocida (80). Estos estudios han provocado intensas discusiones, sobre 
todo en lo que respecta a la persistencia de la disminución del eccema durante un período tan prolongado después de terminada la administración del probiótico.

Un aspecto importante que ha sido necesario precisar es si el efecto positivo del probiótico en las manifestaciones de alergia requiere que el agente esté viable. En un estudio de Kirjavainen y asociados, la administración de Lactobacillus GG inactivado por calor a lactantes con eccema se asoció con diarrea y otras molestias digestivas en 38,4\% del grupo, incluso aunque el SCORAD y las molestias subjetivas asociadas con el eccema mejoraron. La explicación propuesta por los autores es que estos lactantes albergaban en su microbiota colónica números aumentados de clostridios y bacteroides los que en presencia de los lactobacilos inactivados secretaron toxinas diarreicas. Los lactobacilos viables secretan al lumen intestinal enzimas capaces de neutralizar los efectos de estas toxinas, capacidad que está ausente en las bacterias no viables. Otra posibilidad sería que durante el calentamiento los lactobacilos expresan proteínas de shock térmico que modifican sus capacidades inmunoestimuladoras, de forma tal que en vez de ejercer efectos antiinflamatorios tendrían efectos opuestos. Es posible que los probióticos viables estimulen también la producción de interferón (IFN)-g por los linfocitos y otros mononucleares presentes en la mucosa intestinal (81). Manifestaciones similares fueron observadas también en lactantes de 1,5 a 12 meses de edad que sufrían de dermatitis alérgica asociada con la leche de vaca, quienes recibieron Lactobacillus GG solo o asociado con otros probióticos. Algunos lactantes tenían niveles elevados de IgE específica y de IFN-g mientras que en otros la manifestación de atopia no estaba asociada con niveles elevados de IgE ni de IFN-g. Se supone que en estos últimos casos el cuadro alérgico sería causado por mecanismos celulares ya que en los pacientes había además una disminución de la IL-4 circulante, que contrarresta los efectos del IFN-g. Los probióticos, entre ellos Lactobacillus GG, actuarían como contrareguladores del perfil $\mathrm{TH}-2$ de de los lactantes alérgicos y desviarían dicho perfil TH-2, hacia el perfil TH-1, considerado más maduro, en un proceso que normalmente evoluciona entre los 6 y los 18 meses de vida. De manera que a través de modulaciones de la composición de la microbiota intestinal y de la estimulación de los patrones de las respuestas inmunes los probióticos ejercerían efectos positivos sobre la evolución de la alergia a proteínas de la leche de vaca (82). En las heces de pacientes con dermatitis atópica/eccema que recibieron Lactobacillus GG, ya sea aislado o como parte de una mezcla de cuatro probióticos se detectaron descensos de algunos marcadores de inflamación intestinal (83). Al revisar la literatura reciente sobre este tema se observa que mientras que en un número de publicaciones se afirma que Lactobacillus GG ejerce efectos positivos sobre la evolución de los fenómenos alérgicos, para otros autores dichos efectos no son tan evidentes o no existen; en ningún estudio se describen efectos adversos. Bischoff y Crowe recomiendan el uso de Lactobacillus GG para prevenir y tratar las alergias a alimentos (84 en tanto que Viljanen y colaboradores sugieren que el probiótico puede aliviar el eccema atópico/dermatitis en lactantes en quienes su sintomatología está asociada con niveles aumentados de IgE específica circulante pero no en aquellos en quienes estos niveles no están aumentados. Los autores creen que este efecto de Lactobacillus GG obedece a que induce un proceso inflamatorio de baja intensidad que se manifiesta a través de aumentos de la proteína C-reactiva, la IL-6 y la E-selectina. Este probiótico, incorporado a la mezcla de cuatro microorganismos denominada MIX inducía aumentos de la citoquina IL-10, que ejerce efectos antiinflamatorios $(85,86)$. En lactantes alérgicos con hematoquecia que recibieron Lactobacillus GG, los niveles de calprotectina fecal, considerablemente elevados al inicio del tratamiento, descendieron hasta $50 \%$ después de las 4 semanas de tratamiento. Cuando Lactobacillus GG fue incorporado a una fórmula con su proteína extensamente hidrolizada (Nutramigen LGG, Mead Johnson, Ind., USA) el descenso fue más considerable y las 4 semanas ningún lactante (12/12) evidenciaba sangrado rectal; de los lactantes que recibieron la fórmula extensamente hidrolizada control sin Lactobacillus GG, 5/14 continuaron con sangrado $(p=0,002)$ (87). Otro estudio confirmó estos resultados ya que en lactantes de 1 a 12 meses que fueron tratados con Nutramigen la adición de Lactobacillus GG aceleró la aparición de tolerancia para las proteínas de leche de vaca, la que persistió por a lo menos seis meses. Los autores atribuyeron la aparición y la persistencia de dicha tolerancia a la estimulación de la síntesis de IL-4, IL-5, IL-10 e IFN-g, así como de TGF-b y TNF-a en los lactantes en quienes el proceso alérgico era mediado tanto por IgE como por mecanismos celulares sin participación de la IgE. Estos factores contribuyen a regular hacia la disminución los fenómenos inflamatorios propios de la alergia (88). Nuevamente, se trata de un proceso cepa-específico porque otras cepas de lactobacilos administrados en dosis comparables no produjeron resultados comparables (89). Una investigación efectuada en Europa con los mismos probióticos y la misma fórmula láctea con proteína estaba extensamente hidrolizada, confirmó los resultados anteriores (90).

Autores japoneses demostraron en adultos cuya edad promedio era 50 años aproximadamente que el consumo de una leche fermentada que contenía Lactobacillus GG asociado con tres probióticos disminuía después de 9 semanas sus síntomas de obstrucción nasal y la necesidad de fármacos para aliviarlos, en comparación con quienes recibieron placebo. Además, Lactobacilluss GG inhibía in vitro la producción de IL-4 e IL-5 estimulada por fitohemaglutinina en sus mononucleares sanguíneos. Los autores atribuyeron estos efectos a un proceso de regulación hacia la disminución del perfil de reacción TH-2 $(91,92)$. Los mismos autores demostraron que los sujetos con reacción al polen del cedro japonés tenían una menor diversidad de la población de bifidobacterias en su microbiota colónica y que dicha diversidad aumentaba al administrar los probióticos. En su opinión las bifidobacterias de la microbiota fecal pueden llegar a constituir un objetivo de futuros tratamientos $(91,92)$.

Existen publicaciones que no muestran efectos favorables de Lactobacillus GG en la dermatitis atópica de la infancia. En un diseño en doble ciego, controlado con placebo y con confrontación con el alérgeno (iniciales en inglés DBPCFC) Brower y colaboradores administraron una leche extensamente hidrolizada (Nutrilón Pepti Lactobacillus GG o Nutrilón Pepti L. rhamnosus, Nutricia, Cluijk, Holanda) a lactantes con eccema por alergia a proteínas de la leche de vaca. Se evaluó su índice SCORAD y se midieron parámetros de inflamación (a-1-antitripsina en deposiciones y proteína $X$ de eosinófilos en la orina, además de IL-4, IL-5 e IFN-g en su sangre). Se estudiaron 50 y de ellos sólo 14 mostraron una mejoría de su SCORAD de poca intensidad. Ninguno de los parámetros de sensibilización alérgica o de inflamación mostró disminuciones estadísticamente significativas sólo tendencias (93). En un estudio cuyo diseño guarda un estrecho parecido con los de Kalliomäki $(78,79)$ no se observaron beneficios en el SCORAD como resultado de la administración de Lactobacillus GG a la madre durante el embarazo y al lactante durante el postparto; 
más aún, se detectó un aumento de las recurrencias de bronquitis con sibilancias respiratorias. Los autores no recomiendan el uso de Lactobacillus GG en estos casos $(93,94)$. En otro estudio, los efectos de la administración del probiótico fueron evaluados en 76 madres embarazadas quienes recibieron 1,8 $\mathrm{x}$ $10^{10}$ UFC de Lactobacillus GG o un placebo desde la semana 36 de gestación y hasta el parto. No se observaron diferencias en la proliferación de sus linfocitos CD4, en la respuesta a la estimulación de los linfocitos del recién nacido con ovoalbúmina o hemocianina de lapa (keyhole limpet hemocyanin), en la expresión de ARNm de FoxP3 en las células dendríticas o de factores regulación de los procesos de inflamación (IL10, -12 y -13, IFN-g, TGF-b1 y TNF-a). Este estudio indicaría que los efectos de la administración de Lactobacillus GG a la madre embarazada no se transferirían al feto por la vía transplacentaria (95). Un estudio efectuado en Alemania demostró que Lactobacillus GG no ejercería afectos sobre la dermatitis atópica o el asma y sólo tuvo efectos estimados leves sobre los marcadores de sensibilización alérgica, los que persistieron por 6 meses después de suspender el probiótico (96). Aunque a los 2 años se mantenían las mejorías de los fenómenos de sensibilización, cuatro años después no se detectaban efectos sobre los síntomas respiratorios (97). Szajewska y colaboradores no detectaron efectos positivos de Lactobacillus GG en lactantes que experimentaban episodios de sangrado rectal durante la lactancia aunque la madre restringía el consumo de productos lácteos durante dicho período y creen que este probiótico no debería ser empleado en el tratamiento de este cuadro (98).

Es difícil encontrar una explicación para las diferencias entre los resultados al comparar las diversas investigaciones. Es evidente que en el efecto de los probióticos intervienen factores dependientes de la bacteria misma, incluyendo su viabilidad y estado fisiológico, la matriz o el vehículo en que son administradas, la dosis, y su frecuencia así como la duración de su administración. Por otro lado, quien recibe el probiótico, sea madre embarazada, lactante o adulto, interactúa con el agente a través de mecanismos que discriminan a los probióticos de los miembros de la microbiota residente y de los patógenos potenciales. En este proceso participan otros factores propios del individuo: su genética, historia de salud y enfermedad, la maduración funcional de sus sistemas defensivos, su historia nutricional y factores individuales que regulan la calidad de sus respuestas inmunes y cuyo papel es difícil de evaluar. Respecto del efecto de los probióticos hay factores que todavía son poco conocidos. El tubo digestivo mismo, con sus múltiples factores defensivos dispuestos escalonadamente, es un sistema cuya complejidad no se conoce en su totalidad. Con todo, existe irrefutablemente el precedente de que diversas bacterias han sido utilizadas por muchos años en la alimentación y la medicina tradicional y cuyas propiedades son aprovechadas en la actualidad por la ciencia médica y que la población estima positivas; los alimentos y las bacterias que contienen son expendidos sin control estricto y sin que se conozca en todo su detalle cuales son sus mecanismos de acción. Lo que es más importante, pese a su consumo masivo no se han detectado efectos negativos de parte de estas bacterias que alarmen a la comunidad científica.

Lactobacillus GG y cuadros funcionales gastrointestinales. De acuerdo con los criterios de Roma III, los cuadros gastrointestinales relacionados con el dolor abdominal que afectan a los niños pueden ser categorizados como dispepsia funcional, síndrome del intestino irritable, migraña abdominal y dolor abdominal funcional. La fisiopatología de estas manifestaciones no se conoce en todo su detalle y por este motivo hay considerable interés por explorar opciones novedosas de tratamiento, entre ellas el empleo de probióticos (99).

Uno de los primeros ensayos del efecto del LactobacillusGG en relación con el síndrome del intestino irritable en niños fue realizado por Bausserman y Michail (100). Compararon el efecto de este lactobacilo y un placebo administrados por 6 semanas a niños con dolor abdominal recurrente sin encontrar que el probiótico fuera superior. En cambio, dos publicaciones posteriores, a las que se suman comentarios y un meta-análisis, respaldan el concepto de que Lactobacillus GG ejerce efectos positivos sobre las manifestaciones descritas en Roma III (101-105).

Los mecanismos por los cuales Lactobacillus GG ejerce sus afectos en estos cuadros no se conocen en su integridad pero es posible que sean similares a aquellos a través de los cuales L. reuteri ejerce sus efectos sobre el cólico de los lactantes, es decir, a través de bloqueos de la transmisión de impulsos dolorosos a nivel de los ganglios dorsales de la médula espinal y a nivel de núcleos centrales del ssitema nervioso central de donde parten señales eferentes hacia los órganos abdominales (106-110). Este es un campo que ha comenzado a ser explorado recientemente y probablemente alcanzará proyecciones no imaginadas hasta ahora acerca de las relaciones entre la microbiota residente y el cerebro.

\section{RESUMEN}

Los lactobacilos son habitantes normales de las mucosas de los seres humanos; también están presentes en la leche materna. Lactobacillus reuteri fue descrito en la leche de una madre peruana, lo que confirma que estas bacterias son parte de la microbiota que las madres transfieren a sus hijos. El cólico infantil son episodios de llanto excesivo, estridente, por a lo menos 3 horas 3 veces por semana y por a lo menos 3 meses. L. reuteri ATCC 55730 demostró disminuir su intensidad y duración. La etiología del cólico se desconoce pero en las heces de los lactantes afectados se han demostrado disminuciones de los lactobacilos y aumentos de Bacteroides. En 2008 se demostró que L. reuteri ATCC 55730 era portador de plasmidios capaces de resistencia a antibióticos por lo que fue "curado" de estos factores y resultó una nueva cepa, denominada DSM 17938; pruebas in vitro y en animales mostraron su inocuidad y ensayos en humanos revelaron que ejerce las mismas propiedades benéficas que la cepa original. El efecto de L. reuteri en el cólico infantil puede estar relacionado con su capacidad de bloquear en los ganglios dorsales de la medula espinal la transmisión de estímulos a los centros cerebrales superiores. El efecto antirreflujo de L. reuteri se debería a la aceleración del vaciamiento gástrico. Ambas cepas de esta bacteria disminuyen la progresión, morbilidad y mortalidad de la enterocolitis necrosante. Otros efectos en la constipación crónica y la duración de la diarrea aguda de distintas etiologías. L. reuteri sintetiza una molécula, el $\beta$-hidroxipropenal o reuterina, con actividad antibacteriana. Lactobacillus rhamnosus GG ATCC 53103 es probablemente el probiótico más estudiado; acorta la duración de la diarrea aguda, disminuye el número de evacuaciones y la duración de los vómitos e induce mejorías de la diarrea asociada con los tratamientos antibióticos; y disminuiría la intensidad de las infecciones respiratorias altas. Sus efectos se deberían a la estimulación de las inmunidades innata y adquirida y de la activación de los macrófagos y los linfocitos NK. Un efecto notable y discutido de L. ramnosus GG se refiere a sus efectos en la atopia cutánea, ya que disminuiría la extensión e intensidad de sus síntomas, incluso más allá de su administración. También ejercería efectos sobre cuadros 
funcionales gastrointestinales como el síndrome del intestino irritable, por mecanismos aun no elucidados.

Palabras clave: Lactobacillus reuteri ATCC 53730; Lactobacillus reuteri DSM 17938; Lactobacillus rhamnosus GG ATCC 53103; reuterina, diarrea aguda.

\section{BIBLIOGRAFÍA}

1. Kandler $O$, Stetter $K, K o h I R$. Lactobacillus reuteri sp.nov a new species of heterofermentative lactobacilli. Zbl Bakt Hyg Abt Orig 1980; C1: 264-9.

2. Wessel MA, Cobb JC, Jackson EB, Harris GS, Detwiler AC. Paroxismal fussing in infancy, sometimes called "colic". Pediatrics 1954; 14: 421-35.

3. Kirjavainen J, Kirjavainen $T$, Huhtala $V$, Lehtonen $L$, Korvenranta $H$, Kero $P$. J Infants with colic have a normal sleep structure at 2 and 7 months of age. Pediatr 2001; 138: 218-23.

4. Hide DW, Guyer BM. Prevalence of infant colic. Arch Dis Child. 1982; 57: 559-60.

5. Savino F, Cresi F, Pautasso S, Palumeri E, Tullio V, Roana J, Silvestro L, Oggero R. Intestinal microflora in breastfed colicky and non-colicky infants. Acta Paediatr. 2004; 93 : 825-29.

6. Savino F, Pelle E, Palumeri E, Oggero R, Miniero R. Lactobacillus reuteri (American Type Culture Collection Strain 55730) versus simethicone in the treatment of infantile colic: a prospective randomized study. Pediatrics 2007; 119: $124-30$

7. Rosander A, Connolly E, Roos S. Removal of antibiotic resistance gene-carrying plasmids from Lactobacillus reuteri ATCC 55730 and characterization of the resulting daughter strain, L. reuteri DSM 17938. Appl Environ Microbiol. 2008; 74: 6032-40.

8. Savino $F$, Cordisco $L$, Tarasco $V$, Palumeri $E$, Calabrese $R$, Oggero $R$, Roos S, Matteuzzi D. Lactobacillus reuteri DSM 17938 in infantile colic: a randomized, double-blind, placebo-controlled trial. Pediatrics 2010; 126: e526-33.

9. Szajewska H, Gyrczuk E, Horvath A. Lactobacillus reuteri DSM 17938 for the management of infantile colic in breastfed Infants: a randomized, double-blind, placebo-controlled trial. J Pediatr 2012. pii: S0022-3476(12)00920-1.

10. Rousseaux C, Thuru X, Gelot A, Barnich N, Neut C, Dubuquoy L, Dubuquoy C, Merour E, Geboes K, Chamaillard $M$, Ouwehand A, Leyer G, Carcano D, Colombel JF, Ardid $D$, Desreumaux P. Lactobacillus acidophilus modulates intestinal pain and induces opioid and cannabinoid receptors. Nat Med. 2007; 13: 35-7.

11. Kunze WA, Mao YK, Wang $B$, Huizinga JD, Ma X, Forsythe $P$, Bienenstock J. Lactobacillus reuteri enhances excitability of colonic $\mathrm{AH}$ neurons by inhibiting calcium-dependent potassium channel opening. J Cell Mol Med. 2009; 13: 2261-70.

12. Wang $B$, Mao $Y K$, Diorio $C$, Wang $L$, Huizinga JD, Bienenstock J, Kunze W. Lactobacillus reuteri ingestion and IK(Ca) channel blockade have similar effects on rat colon motility and myenteric neurones. Neurogastroenterol Motil 2010; 22: 98-107.

13. Ma X, Mao YK, Wang B, Huizinga JD, Bienenstock J, Kunze $W$. Lactobacillus reuteri ingestion prevents hyperexcitability of colonic DRG neurons induced by noxious stimuli. Am J Physiol Gastrointest Liver Physiol. 2009; 296: G868-75.

14. Bercik P, Park AJ, Sinclair D, Khoshdel A, Lu J, Huang $X$, Deng $Y$, Blennerhassett PA, Fahnestock M, Moine D, Berger $B$, Huizinga JD, Kunze W, McLean PG, Bergonzelli
GE, Collins SM, Verdu EF. The anxiolytic effect of Bifidobacterium longum NCC3001 involves vagal pathways for gut-brain communication. Neurogastroenterol Motil 2011; 23: 1132-9.

15. Indrio F, Riezzo G, Raimondi F, Bisceglia M, Cavallo L, Francavilla $R$. The effects of probiotics on feeding tolerance, bowel habits and gastrointestinal motility in premature newborns. J Pediatr. 2008; 152: 801-06.

16. Hunter, C, Dimaguila MAT, Gal P, Wimmer JE, Ransom $J L$, Carlos RQ, Smith MCC, Davanzo C. Effect of routine probiotic, Lactobacillus reuteri DSM 17938, use on rates of necrotizing enterocolitis in neonates with birthweight <1000 grams: a sequential study. BMC Pediatrics 2012; 12: 142-7.

17. Coccurullo P, Strisciuglio C, Martinelli M, Miele M, Greco L, Staiano A. Lactobacillus reuteri DSM 17938) in infants with functional chronic constipation: a doule-blind, randomized, placebo controlled study. J Pediatr. 2010; 157: 598-602.

18. Romano $C$, Ferrau $V$, Cavataio $F$, lacono $G$, Spina M, Lionetti $E$, Comisi F, Famiani A, Comito D. Lactobacillus reuteri in children with functional abdominal pain (FAP). J Paediatr Child Health. $2010 \mathrm{Jul}$ 8. [Epub ahead of print]

19. Storr MA, Yüce $B$, Andrews CN, Sharkey KA. The role of the endocannabinoid system in the pathophysiology and treatment of irritable bowel syndrome. Neurogastroenterol Motil. 2008; 20: 857-68.

20. Wanke M, Szajewska H. Lack of an effect of Lactobacillus reuteri DSM 17938 in preventing nosocomial diarrhea in children: a randomized, double-blind, placebo-controlled trial. J Pediatr. 2012; 161: 40-3.

21. Savino F, Cordisco L, Tarasco V, Calabrese $R$, Palumeri $E$, Matteuzzi D. Molecular identification of coliform bacteria from colicky breastfed infants. Acta Paediatr. 2009; 98: 1582-8.

22. Saavedra JM, Bauman NA, Oung I, Perman JA, Yolken RH. Feeding of Bifidobacterium bifidum and Streptococcus thermophilus to infants in hospital for prevention of diarrhoea and shedding of rotavirus. Lancet 1994; 344: 1046-9.

23. Francavilla $R$, Lionetti $E$, Castellaneta $S$, Ciruzzi $F$, Indrio $F$, Masciale A, Fontana C, La Rosa MM, Cavallo L, Francavilla A. Randomised clinical trial: Lactobacillus reuteri DSM 17938 vs. placebo in children with acute diarrhoea--a double-blind study. Aliment Pharmacol Ther. 2012; 36: 363-9.

24. Shornikova AV, Casas IA, Isolauri E, Mykkänen H, Vesikari T. Lactobacillus reuteri as a therapeutic agent in acute diarrhea in young children. J Pediatr Gastroenterol Nutr 1997: 24: 399-404.

25. Talarico TL, Casas IA, Chung TC, Dobrogosz WJ. Production and isolation of reuterin, a growth inhibitor produced by Lactobacillus reuteri. Antimicrob Agents Chemother. 1988 Dec;32(12):1854-8.

26. Francavilla $R$, Lionetti $E$, Castellaneta $S P$, Magistà $A M$, Maurogiovanni G, Bucci N, De Canio A, Indrio F, Cavallo $L$, lerardi E, Miniello VL. Inhibition of Helicobacter pylori infection in humans by Lactobacillus reuteri ATCC 55730 and effect on eradication therapy: a pilot study. Helicobacter 2008; 13: 127-34.

27. Branton $W B$, Jones $M L$, Tomaro-Duchesneau C, Martoni CJ, Prakash S. In vitro characterization and safety of the probiotic strain Lactobacillus reuteri Cardioviva NCIMB 30242, Int J Probiotics Prebiotics 2011: 6: 1-12.

28. Jones ML, Martoni CJ, Parent M, Prakash S. Cholesterol- 
lowering efficacy of a microencapsulated bile salt hydrolase-active Lactobacillus reuteri NCIMB 30242 yoghurt formulation in hypercholesterolaemic adults $\mathrm{Br} J$ Nutr. 2012; 107: 1505-13.

29. Jones ML, Martoni CJ, Tamber S, Parent M, Prakash. Evaluation of safety and tolerance of microencapsulated Lactibacillus reuteri NCIMB 30242 in a yogourt formulation: a randomized, placebo controlled, double-blind study. Food Chem Toxicol. 2012: 50: 2216-23.

30. Jones ML, Martoni CJ, Di Pietro E, Simon RR, Prakash S. Evaluation of clinical safety and tolerance of a Lactobacillus reuteri NCIMB 30242 supplement capsule: a randomized control trial. Regul Toxicol Pharmacol. 2012; 63:313-20.

31. Jones ML, Martoni CJ, Prakash S. Cholesterol lowering and inhibition of sterol absorption by Lactobacillus reuteri NCIMB 30242: a randomized controlled trial. Eur J Clin Nutr. 2012; 66: 1234-41.

32. Shornikova AV, Casas IA, Mykkänen H, Salo E, Vesikari T. Bacteriotherapy with Lactobacillus reuteri in rotavirus gastroenteritis. Pediatr Infect Dis J. 1997;16:1103-7.

33. Weizman Z, Asli G, Alsheikh A. Effect of a probiotic infant formula on infections in child care centers: comparison of two probiotic agents. Pediatrics 2005; 115: 5-9.

34. de Vrese M, Marteau PR. Probiotics and prebiotics: effects on diarrhea. J Nutr 2007; 137(3 Suppl 2): 803S-11S.

35. Francavilla $R$, Lionetti $E$, Castellaneta S, Ciruzzi F, Indrio $F$, Masciale A, Fontana C, La Rosa MM, Cavallo L, Francavilla A. Randomised clinical trial: Lactobacillus reuteri DSM 17938 vs. placebo in children with acute diarrhoea--a double-blind study. Aliment Pharmacol Ther. 2012; 36: 363-9.

36. Agustina $R$, Kok FJ, van de Rest O, Fahmida U, Firmansyah A, Lukito W, Feskens EJ, van den Heuvel EG, Albers $R$, Bovee-Oudenhoven IM. Randomized trial of probiotics and calcium on diarrhea and respiratory tract infections in Indonesian children. Pediatrics 2012; 129:e1155-64.

37. Ojetti V, Bruno $G$, Ainora ME, Gigante $G$, Rizzo G, Roccarina D, Gasbarrini A. Impact of Lactobacillus reuteri supplementation on anti-Helicobacter pylori levofloxacinbased second-line therapy. Gastroenterol Res Pract. 2012;2012:740381.

38. Szajewska H, Wanke M, Patro B. Meta-analysis: the effects of Lactobacillus rhamnosus GG supplementation for the prevention of healthcare-associated diarrhoea in children. Aliment Pharmacol Ther. 2011; 34: 1079-87.

39. Rosenfeldt $V$, Michaelsen $K F$, Jakobsen $M$, Larsen $C N$, Møller PL, Pedersen P, Tvede M, Weyrehter $H$, Valerius NH, Paerregaard A. Effect of probiotic Lactobacillus strains in young children hospitalized with acute diarrhea. Pediatr Infect Dis J. 2002; 21: 411-6.

40. Silva M, Jacobus NV, Deneke C, Gorbach SL. Antimicrobial substance from a human Lactobacillus strain. Antimicrob Agents Chemother. 1987; 31: 1231-1233.

41. Goldin BR, Gorbach SL, Saxelin M, Barakat S, Gualtieri L, Salminen S. Survival of Lactobacillus species (strain GG) in human gastrointestinal tract. Dig Dis Sci 1992; 37: 121-8.

42. Alander $M$, Satokari $R$, Korpela $R$, Saxelin M, VilpponenSalmela $T$, Mattila-Sandholm T, von Wright A. Persistence of colonization of human colonic mucosa by a probiotic strain, Lactobacillus rhamnosus GG, after oral consumption. Appl Environ Microbiol. 1999; 65: 351-4.

43. Petschow BW, Figueroa $R$, Harris $C L$, Beck $L B$, Ziegler $E$, Goldin B. Effects of feeding an infant formula containing Lactobacillus GG on the colonization of the intestine: $a$ dose-response study in healthy infants. J Clin Gastroenterol. 2005; 39: 786-90.

44. Dommels YE, Kemperman RA, Zebregs YE, Draaisma RB, Jol A, Wolvers DA, Vaughan EE, Albers $R$. Survival of Lactobacillus reuteri DSM 17938 and Lactobacillus rhamnosus GG in the human gastrointestinal tract with daily consumption of a low-fat probiotic spread. Appl Environ Microbiol. 2009; 75: 6198-204.

45. Majamaa $H$, Isolauri E, Saxelin M, Vesikari T. Lactic acid bacteria in the treatment of acute rotavirus gastroenteritis. J Pediatr Gastroenterol Nutr.1995; 20: 333-38.

46. Shornikova AV, Isolauri E, Burkanova L, Lukovnikova S, Vesikari T. A trial in the Karelian Republic of oral rehydration and Lactobacillus GG for treatment of acute diarrhoea. Acta Paediatr. 1997; 86: 460-5.

47. De Keersmaecker SC, Verhoeven TL, Desair J, Marchal $K$, Vanderleyden J, Nagy I. Strong antimicrobial activity of Lactobacillus rhamnosus GG against Salmonella typhimurium is due to accumulation of lactic acid. FEMS Microbiol Lett. 2006; 259:89-96.

48. Szajewska H, Skórka A, Ruszczyński M, Gieruszczak-Białek D. Meta-analysis: Lactobacillus GG for treating acute diarrhoea in children. Aliment Pharmacol Ther. 2007; 25: 871-81.

49. Berni Canani $R$, Cirillo $P$, Terrin $G$, Cesarano L, Spagnuolo MI, De Vincenzo A, Albano F, Passariello A, De Marco G, Manguso F, Guarino A. Probiotics for treatment of acute diarrhoea in children: randomised clinical trial of five different preparations. BMJ 2007; 335: 40.

50. Szymański H, Pejcz J, Jawień M, Chmielarczyk A, Strus $M$, Heczko PB. Treatment of acute infectious diarrhoea in infants and children with a mixture of three Lactobacillus rhamnosus strains - a randomized, double-blind, placebo-controlled trial. Aliment Pharmacol Ther. 2006; 23: 247-53.

51. de Vrese M, Marteau PR. Probiotics and prebiotics: effects on diarrhea. J Nutr. 2007; 137(3 Supp/ 2): 803S-11S.

52. Pieścik-Lech M, Urbańska M, Szajewska H. Lactobacillus GG (LGG) and smectite versus LGG alone for acute gastroenteritis: a double-blind, randomized controlled trial. Eur J Pediatr. 2012 Nov 1. [Epub ahead of print]

53. Misra S, Sabui TK, Pal NK. A randomized controlled trial to evaluate the efficacy of Lactobacillus GG in infantile diarrhea. J Pediatr. 2009; 155: 129-32.

54. Ferrie S, Daley M. Lactobacillus GG as treatment for diarrhea during enteral feeding in critical illness: randomized controlled trial. JPEN J Parenter Enteral Nutr. 2011; 35: 43-9.

55. Ritchie $B K$, Brewster DR, Tran CD, Davidson GP, McNeil $Y$, Butler RN. Efficacy of Lactobacillus GG in aboriginal children with acute diarrhoeal disease: a randomised clinical trial. J Pediatr Gastroenterol Nutr. 2010; 50: 619-24.

56. Salazar-Lindo $E$, Miranda-Langschwager P, Campos-Sanchez M, Chea-Woo E, Sack RB. Lactobacillus casei strain GG in the treatment of infants with acute watery diarrhea: a randomized, double-blind, placebo controlled clinical trial [ISRCTN67363048]. BMC Pediatr. 2004 2;4-18.

57. Guandalini S. Probiotics for children with diarrhea: an update. J Clin Gastroenterol. 2008; 42 Suppl 2: S53-7.

58. Pieścik-Lech M, Urbańska M, Szajewska H. Lactobacillus GG (LGG) and smectite versus LGG alone for acute gastroenteritis: a double- blind, randomized controlled trial. Eur J Pediatr. 2012 Nov 1 [Epub ahead of print].

59. Arvola T, Laiho K, Torkkeli S, Mykkänen H, Salminen 
S, Maunula L, Isolauri E. Prophylactic Lactobacillus GG reduces antibiotic-associated diarrhea in children with respiratory infections: a randomized study. Pediatrics 1999 Nov;104(5):e64.

60. Ellison RT 3rd. Review: probiotics are effective for prevention of antibiotic-associated diarrhea and treatment of Clostridium difficile disease. ACP J Club 2006; 145: 46.

61. McFarland LV. Meta-analysis of probiotics for the prevention of antibiotic associated diarrhea and the treatment of Clostridium difficile disease. Am J Gastroenterol. 2006; 101: 812-22.

62. Floch $M H$, Walker WA, Guandalini S, Hibberd P, Gorbach S, Surawicz C, Sanders ME, Garcia-Tsao G, Quigley EM, Isolauri E, Fedorak RN, Dieleman LA. Recommendations for probiotic use: 2008. J Clin Gastroenterol. 2008; 42 Suppl 2: S104-8.

63. Louhiala PJ, Jaakkola N, Ruotsalainen R, Jaakkola JJ. Form of day care and respiratory infections among Finnish children. Am J Public Health. 1995; 85 (8 Pt 1): 1109-12.

64. Hatakka K, Savilahti E, Pönkä A, Meurman JH, Poussa T, Näse L, Saxelin M, Korpela R. Effect of long term consumption of probiotic milk on infections in children attending day care centres: double blind, randomised trial. BMJ 2001; 322: 1327.

65. Hojsak I, Snovak N, Abdović S, Szajewska H, Misak Z, Kolacek S. Lactobacillus GG in the prevention of gastrointestinal and respiratory tract infections in children who attend day care centers: a randomized, double-blind, placebo-controlled trial. Clin Nutr. 2010; 29: 312-16.

66. Hojsak I, Abdović S, Szajewska H, Milosević M, Krznarić Z, Kolacek S. Lactobacillus GG in the prevention of nosocomial gastrointestinal and respiratory tract infections. Pediatrics 2010; 125: e1171-7.

67. Kumpu M, Kekkonen RA, Kautiainen $H$, Järvenpää $S$, Kristo A, Huovinen P, Pitkäranta A, Korpela R, Hatakka K. Milk containing probiotic Lactobacillus rhamnosus GC and respiratory illness in children: a randomized, doubleblind, placebo-controlled trial. Eur J Clin Nutr. 2012; 66: 1020-23.

68. Bunselmeyer B, Butddendick K. Probiotics and prebiotics Prevention and therapy in atopic eczema. En: DR Watson, VR Preedy, editors. Bioactive foods in promoting health: probiotics and prebiotics. $1^{a}$ edición. San Diego: Academic Press, Inc. 2010; 279-92.

69. Yan F, Cao H, Cover TL, Washington MK, Shi Y, Liu L, Chaturvedi R, Peek RM Jr, Wilson KT, Polk DB. Colonspecific delivery of a probiotic-derived soluble protein ameliorates intestinal inflammation in mice through an EGFR-dependent mechanism. J Clin Invest. 2011; 121: 2242-53.

70. Aberg N, Hesselmar B, Aberg B, Eriksson B. Increase of asthma, allergic rhinitis and eczema in Swedish schoolchildren between 1979 and 1991. Clin Exp Allergy. 1995; 25: 815-9.

71. Ninan TK, Russell G. The changing picture of childhood asthma. Paediatr Respir Rev. 2000; 1: 71-78.

72. Otters $H B$, van der Wouden JC, Schellevis FG, van Suijlekom-Smit LW, Koes BW. Changing morbidity patterns in children in Dutch general practice: 1987-2001. Eur J Gen Pract. 2005; 11: 17-22.

73. Sicherer SH, Muñoz-Furlong A, Godbold JH, Sampson HA. US prevalence of self-reported peanut, tree nut, and sesame allergy: 11-year follow-up. J Allergy Clin Immunol. 2010; 125: $1322-26$.
74. Toh ZQ, Anzela A, Tang ML, Licciardi PV. Probiotic therapy as a novel approach for allergic disease. Front Pharmacol. 2012; 3:171. Epub 2012 Sep 21.

75. Zuidmeer L, Goldhahn K, Rona RJ, Gislason D, Madsen C, Summers C, Sodergren E, Dahlstrom J, Lindner T, Sigurdardottir ST, McBride D, Keil T. The prevalence of plant food allergies: a systematic review. J Allergy Clin Immunol. 2008; 121: 1210-18.18.

76. Rona RJ, Keil T, Summers C, Gislason D, Zuidmeer L, Sodergren E, Sigurdardottir ST, Lindner T, Goldhahn K, Dahlstrom J, McBride D, Madsen C. The prevalence of food allergy: a meta-analysis. J Allergy Clin Immunol. 2007; 120: 638-46.

77. Kalliomäki M, Salminen S, Arvilommi H, Kero P, Koskinen $P$, Isolauri E. Probiotics in primary prevention of atopic disease: a randomised placebo-controlled trial. Lancet 2001; 357: 1076-9.

78. Kalliomäki M, Salminen S, Poussa T, Arvilommi H, Isolauri E. Probiotics and prevention of atopic disease: 4-year follow-up of a randomised placebo-controlled trial. Lancet 2003; 361: 1869-71.

79. Kalliomäki M, Salminen S, Poussa T, Isolauri E. Probiotics during the first 7 years of life: a cumulative risk reduction of eczema in a randomized, placebo-controlled trial. I Allergy Clin Immunol. 2007; 119: 1019-21.

80. Kirjavainen PV, Salminen SJ, Isolauri E. Probiotic bacteria in the management of atopic disease: underscoring the importance of viability. J Pediatr Gastroenterol Nutr. 2003; 36: 223-27.

81. Pohjavuori $E$, Viljanen $M$, Korpela $R$, Kuitunen $M$, Tiittanen $M$, Vaarala $O$, Savilahti E. Lactobacillus GG effect in increasing IFN-gamma production in infants with cow's milk allergy. J Allergy Clin Immunol. 2004; 114: 131-6.

82. Viljanen $M$, Kuitunen M, Haahtela T, Juntunen-Backman $K$, Korpela $R$, Savilahti $E$. Probiotic effects on faecal inflammatory markers and on faecal IgA in food allergic atopic eczema/dermatitis syndrome infants. Pediatr Allergy Immunol. 2005; 16: 65-71.

83. Bischoff S, Crowe SE. Food allergy and the gastrointestinal tract. Curr Opin Gastroenterol. 2004; 20: 156-61.

84. Viljanen M, Pohjavuori E, Haahtela T, Korpela R, Kuitunen M, Sarnesto A, Vaarala $O$, Savilahti E. Induction of inflammation as a possible mechanism of probiotic effect in atopic eczema-dermatitis syndrome. J Allergy Clin Immunol. 2005; 115: 1254-9.

85. Viljanen $M$, Savilahti E, Haahtela T, Juntunen-Backman $K$, Korpela R, Poussa T, Tuure T, Kuitunen M. Probiotics in the treatment of atopic eczema/dermatitis syndrome in infants: a double-blind placebo-controlled trial. Allergy 2005; 60: 494-500.

86. Baldassarre ME, Laforgia N, Fanelli M, Laneve A, Grosso R, Lifschitz C. Lactobacillus GG improves recovery in infants with blood in the stools and presumptive allergic colitis compared with extensively hydrolyzed formula alone. J Pediatr. 2010; 156: 397-401.

87. Berni Canani $R$, Nocerino $R$, Terrin $G$, Coruzzo A, Cosenza $L$, Leone $L$, Troncone R. Effect of Lactobacillus GG on tolerance acquisition in infants with cow's milk allergy: a randomized trial. J Allergy Clin Immunol. 2012; 129: 580-2.

88. Mileti E, Matteoli G, Iliev ID, Rescigno M. Comparison of the immunomodulatory properties of three probiotic strains of Lactobacilli using complex culture systems: prediction for in vivo efficacy. PLoS One 2009:16;4 (9):e7056.

89. Muraro A, Hoekstra MO, Meijer Y, Lifschitz C, Wampler $J L$, Harris C, Scalabrin DM. Extensively hydrolysed casein 
formula supplemented with Lactobacillus rhamnosus GG maintains hypoallergenic status: randomised double-blind, placebo-controlled crossover trial. BMJ Open. 2012; 2: e000637.

90. Kawase M, He F, Kubota A, Hiramatsu M, Saito H, Ishii T, Yasueda $H$, Akiyama K. Effect of fermented milk prepared with two probiotic strains on Japanese cedar pollinosis in a double-blind placebo-controlled clinical study. Int J Food Microbiol. 2009; 128: 429-34.

91. Kubota A, He F, Kawase M, Harata $G$, Hiramatsu M, lino $H$. Diversity of intestinal bifidobacteria in patients with Japanese cedar pollinosis and possible influence of probiotic intervention. Curr Microbiol. 2011; 62: 71-7.

92. Brouwer $M L$, Wolt-Plompen SA, Dubois AE, van der Heide $S$, Jansen DF, Hoijer MA, Kauffman HF, Duiverman EJ. No effects of probiotics on atopic dermatitis in infancy: a randomized placebo-controlled trial. Clin Exp Allergy. 2006; 36: 899-906.

93. Kopp MV, Hennemuth I, Heinzmann A, Urbanek R. Randomized, double-blind, placebo-controlled trial of probiotics for primary prevention: no clinical effects of Lactobacillus GG supplementation. Pediatrics 2008; 121: e850-56.

94. Boyle RJ, Mah LJ, Chen A, Kivivuori S, Robins-Browne RM, Tang ML. Effects of Lactobacillus GG treatment during pregnancy on the development of fetal antigen-specific immune responses. Clin Exp Allergy. 2008; 38: 1882-90.

95. Rose MA, Stieglitz F, Köksal A, Schubert R, Schulze J, Zielen S. Efficacy of probiotic Lactobacillus GG on allergic sensitization and asthma in infants at risk. Clin Exp Allergy. 2010; 40: 1398-405.

96. Rose MA, Schubert $R$, Schulze J, Zielen S. Follow-up of probiotic Lactobacillus GG effects on allergic sensitization and asthma in infants at risk. Clin Exp Allergy. 2011; 41: 1819-21.

97. Szajewska H, Gawronska A, Wos $H$, Banaszkiewicz A, Grzybowska-Chlebowczyk U. Lack of effect of Lactobacillus GG in breast-fed infants with rectal bleeding: a pilot double-blind randomized controlled trial. J Pediatr Gastroenterol Nutr. 2007; 45: 247-51.

98. Hyman PE, Milla PJ, Benninga MA, Davidson GP, Fleisher $D F$, Taminiau J. Childhood functional gastrointestinal disorders: neonate/toddler. Gastroenterology 2006; 130: 1519-26.
99. Bausserman M, Michail S. The use of Lactobacillus GG in irritable bowel syndrome in children: a double-blind randomized control trial. J Pediatr. 2005; 147: 197-201.

100. Gawrońska A, Dziechciarz P, Horvath A, Szajewska H. $A$ randomized double-blind placebo-controlled trial of Lactobacillus GG for abdominal pain disorders in children. Aliment Pharmacol Ther. 2007; 25: 177-84.

101. Francavilla $R$, Miniello V, Magistà AM, De Canio A, Bucci $N$, Gagliardi F, Lionetti E, Castellaneta S, Polimeno L, Peccarisi L, Indrio F, Cavallo L. A randomized controlled trial of Lactobacillus GG in children with functional abdominal pain. Pediatrics 2010; 126: e1445-52.

102. Abu-Salih M, Dickinson CJ. Lactobacillus GG may improve frequency and severity of pain in children with functional abdominal pain. J Pediatr. 2011; 159: 165-6.

103. Vandenplas Y, Benninga M. Probiotics and functional gastrointestinal disorders in children. J Pediatr Gastroenterol Nutr 2009; 48 Suppl 2: S107-09.

104. Horvath A, Diechciarz P, Szajewska H. Meta-analysis: Lactobacillus rhamnossus GG for abdominal pain-related functional gastrointestinal disorders in childhood. Aliment Pharmacol Ther.2011; 33: 1302-10.

105. Kunze WA, Mao YK, Wang B, Huizinga JD, Ma X, Forsythe $P$, Bienenstock J. Lactobacillus reuteri enhances excitability of colonic $\mathrm{AH}$ neurons by inhibiting calcium-dependent potassium channel opening. I Cell Mol Med. 2009; 13: 2261-70.

106. Wang B, Mao YK, Diorio C, Wang L, Huizinga JD, Bienenstock J, Kunze W. Lactobacillus reuteri ingestion and IK(Ca) channel blockade have similar effects on rat colon motility and myenteric neurones. Neurogastroenterol Motil. 2010; 22: 98-107.

107. Ma X, Mao YK, Wang B, Huizinga JD, Bienenstock J, Kunze $W$. Lactobacillus reuteri ingestion prevents hyperexcitability of colonic DRG neurons induced by noxious stimuli. Am J Physiol Gastrointest Liver Physiol. 2009; 296: G868-75.

108. Bercik P, Park AJ, Sinclair D, Khoshdel A, Lu J, Huang $X$, Deng Y, Blennerhassett PA, Fahnestock M, Moine D, Berger $B$, Huizinga JD, Kunze W, McLean PG, Bergonzelli GE, Collins SM, Verdu EF. The anxiolytic effect of Bifidobacterium longum NCC3001 involves vagal pathways for gut-brain communication. Neurogastroenterol Motil. 2011; 23: 1132-9. 


\title{
El papel de las bifidobacterias en el funcionamiento del organismo humano
}

\author{
Role of bifidobacteria in the function \\ of the human body
}

\begin{abstract}
Bifidobacterium animalis ssp lactis Bb12 is a probiotic strain that has received considerable attention from the scientific community. It has tolerance to higher temperatures and lower, acidic $\mathrm{pH}$ than other bacteria. When administered for 12 months to infants and children together with $S$. thermophilus this was associated with lower incidences of acute diarrhea. Studies in different countries and with different experimental designs confirmed these results. It was also shown that its administration did not interfere the growth or the normal weight gain of the children. Bifidobacterium animalis ssp lactis Bb12 was associated with decreases of the fecal excretion of rotavirus during episodes of diarrhea, a fact that represents an epidemiological benefit. Bifidobacterium animalis ssp lactis Bb12 exerts positive effects on manifestations of atopy/eczema, with decreases of the parameters of inflammation such as CD4 in blood serum and eosinophil protein $X$ in urine. This was associated with changes in the extension and severity of the skin lesions. No modifications of the normal growth parameters were observed when Bifidobacterium animalis ssp lactis CNCM I-3446 was given. Administration of Bifidobacterium animalis ssp lactis Bb12 is associated with higher levels of fecal slgA and calprotectin, which are considered parameters of immune responses and of the capacity to launch inflammatory responses. The statements made by some groups that infants under 4 months of age who are not breastfed should not receive probiotics have weak support if it is considered that maternal milk contains a large number and variety of strains of bacteria which may be considered as probiotics. These may not only protect from acute diarrhea but also from upper respiratory infections. Although cases of septicemia due to probiotic have been reported these represent an infinitely small proportion of the total numbers of consumers. No outbreaks have been reported that would point to invasive properties in a strain. It is not advisable to administer any living bacteria to individuals in shock or with innate or severe defects of immunity. However, carriers of HIV or patients with AIDS benefit from probiotic agents. A study carried out in Chile showed that although without evident clinical benefits L. rhamnosus HNO01, significantly increased fecal slgA as a manifestation of improved mucosal defense in the digestive tract.

Key words: Bifidobacterium animalis ssp lactis Bb12; acute diarrhea; secretory immunoglobulin A, immunity, human immunodeficiency virus (HIV), acquired immunodeficiency syndrome (AIDS).
\end{abstract}

De las múltiples especies de bifidobacterias que colonizan el organismo humano, Bifidobacterium animalis ssp lactis es una de las más estudiadas y una de sus cepas, la denominada Bb12 tiene amplio uso en nutrición humana.

Bifidobacterium animalis ssp lactis es un anaerobio Grampositivo que se encuentra frecuentemente en el intestino de
Oscar Brunser T.

Representante en Chile, Nestlé Nutrition Institute Santiago, Chile

Dirigir la correspondencia a:

Oscar Brunser T.

Profesor de Pediatría, Universidad de Chile Avda. Las Condes 11287 - 50 Piso - Las Condes Santiago - Chile

E-mail: oscar.brunser@CL.nestle.com

Este trabajo fue recibido el 9 de Julio de 2013 y aceptado para ser publicado el 27 de Agosto de 2013.

los seres humanos. Bifidobacterium animalis y Bifidobacterium lactis fueron considerados especies separadas pero en la actualidad están clasificados como Bifidobacterium animalis subespecie animalis y Bifidobacterium animalis subespecie lactis, del que Bb12 es una cepa; las denominaciones antiguas aún están en uso en el etiquetado de alimentos. Bifidobacterium animalis 
ssp lactis Bb12 es capaz de crecer a temperaturas elevadas para este tipo de microorganismos $\left(41^{\circ}-43^{\circ} \mathrm{C}\right)$ y es más tolerante a los ambientes ácidos en comparación con otras bacterias de origen humano, lo que favorece su utilización en procesos industriales de la producción de algunos alimentos (1).

Un estudio efectuado en Francia evaluó la eficacia de Bifidobacterium animalis ssp lactis Bb12 en la prevención de diarrea aguda en 90 lactantes menores de 8 meses de edad que concurrían a guarderías infantiles o permanecían en colocación familiar por al menos 4 meses. De ellos 46 lactantes recibieron la fórmula con el probiótico y los otros 44 sirvieron de control. Ambos grupos fueron comparables al ingreso en cuanto a sus características antropométricas. De los lactantes que recibieron el probiótico, 28,3\% experimentaron episodios de diarrea en comparación con $38,7 \%$ en el grupo control. El número de días con diarrea por episodio fue 1,2 $\pm 2,5$ en el grupo que recibió el probiótico, con una probabilidad diaria de desarrollar un episodio de 0,84 en comparación con 2,3 \pm 4,5 días de duración de la diarrea y una probabilidad diaria de un episodio de 1,6 en el grupo control ( $p<0,0002$ y 0,0014, respectivamente). El consumo de la fórmula con Bb12 disminuyó el riesgo de diarrea por un factor de 1,9 (rango 1,33-2,60). Según los autores, estos resultados apoyan la hipótesis de que Bifidobacterium animalis ssp lactis Bb12 agregado a una leche acidificada otorga protección frente a la diarrea aguda (2).

Otros investigadores publicaron resultados que apoyan estos hallazgos iniciales. Saavedra y colaboradores evaluaron los efectos de una mezcla de Bifidobacterium lactis y $\mathrm{S}$. thermophilus administrada durante 18 meses a lactantes sanos de 3 a 24 meses de edad al ser incorporados al estudio. Sus hallazgos incluyeron una disminución de la frecuencia de cólicos y de irritabilidad ( $p<0,001)$ y menor necesidad de recurrir al uso de antibióticos $(p<0,001)$. En cambio no hubo diferencias en la velocidad de crecimiento, el ausentismo a las guarderías infantiles y en otras variables relacionadas con la salud (3). Otro estudio efectuado en guarderías infantiles en Israel demostró que en comparación con el grupo control la administración de Bifidobacterium animalis ssp lactis Bb12 a niños de guarderías infantiles estaba asociada con un menor número de episodios febriles y de diarrea, que eran de menor duraciónn ( $p<0,001)(4)$. La ausencia de repercusiones tanto negativas como positivas por parte del probiótico sobre el crecimiento del peso y la talla fue explorada por los mismos autores en otra publicación (5).

Los efectos de Bifidobacterium Bb12 en la diarrea aguda también han sido explorados en otros estudios. Este probiótico, administrado en un cereal en asociación con $S$. thermophilus, L. acidophilus y zinc disminuyó la duración de los episodios de diarrea aunque no queda en claro cual habría sido el efecto de cada uno de ellos aisladamente efectúen distintas combinaciones; además el número de niños tratados fue relativamente bajo (6). En otro estudio se comparó la administración de dos niveles de Bifidobacterium Bb12 (108 UFC y $10^{9}$ UFC por gramo del polvo) en una fórmula sin lactosa que además contenía $S$. thermophilus $\left(5 \times 10^{7}\right.$ o $5 \times 10^{8}$ UFC por gramo de fórmula en polvo) y se evaluó, entre otros parámetros, la duración de la diarrea y la excreción de rotavirus. La dosis más elevada de Bifidobacterium animalis ssp lactis Bb12 se asoció con una menor excreción fecal de rotavirus, lo que puede tener importancia epidemiológica porque contribuiría a disminuir la eficiencia de la transmisión del virus (9).

El efecto de Bifidobacterium lactis fue comparado con Saccharomyces boulardii en niños de 5 meses a 5 años de edad afectados por episodios de diarrea líquida y deshidrata- ción leve. Los lactantes que recibieron Bifidobacterium lactis tuvieron episodios cuya evolución fue significativamente más corta $(4,1 \pm 1,3$ días) que en aquellos que recibieron $S$. boulardii $(6,61 \pm 1,7$ días) o que en el grupo control $(7,0 \pm 1,6$ días) ( $p$ $<0,001$ Bifidobacterium lactis vs S. boulardii o control). Estos resultados refuerzan el concepto de que Bifidobacterium lactis Bb12 podría ejercer un efecto específico en los episodios de diarrea por rotavirus, comparable con lo publicado para algunos lactobacilos (8).

Tempranamente en el estudio de los probióticos resultó evidente que estos microorganismos ejercen efectos sobre la calidad de las respuestas inmunes y se despertó especial interés respecto de las reacciones alérgicas, en especial la atopia/ eccema. En un estudio, lactantes con este tipo de patologías que nunca habían sido expuestos a fórmulas lácteas fueron destetados con una fórmula que contenía proteínas de suero extensamente hidrolizadas y Bifidobacterium Bb12 o Lactobacillus GG. EI SCORAD inicial durante el amamantamiento fue 16 y después de 2 meses descendió significativamente $\left(X^{2}\right.$ $=12,27, p=0,002)$ : en quienes recibieron Bifidobacterium Bb12 a 0 (margen: $0-3,8$ ) y en quienes recibieron Lactobacillus GG a 1 (margen $0,1-8,7$ ). En cambio en el grupo control, no suplementado con probióticos, la mediana del SCORAD fue 13,4 (margen intercuartil 4,5-18,2). Junto con el descenso del SCORAD, los niños que recibieron probióticos experimentaron descensos de CD4 soluble en el suero y de la proteína $X$ de eosinófilos en la orina (9). Esta es una demostración de que cepas específicas de probióticos son capaces de modificar parámetros asociados con la inflamación alérgica cutánea y de producir efectos beneficiosos más allá del tubo digestivo. Uno de los mecanismos que pueden explicar esta respuesta es el aumento de la calidad de la barrera intestinal. Stratiki y colaboradores observaron que al administrar Bifidobacterium Bb12 (2,7 x 107 UFC/gramo de fórmula en polvo) a prematuros estabilizados de entre 27 y 36 semanas de gestación se observaban aumentos de la excreción fecal de bifidobacterias ( $p=0,036$ versus el control); estos niveles se permanecían elevados, aunque no significativamente, al día $30(p=0,075)$. Ese día, que marcaba término del estudio, la relación lactulosa/manitol en la orina era significativamente más baja en el grupo que recibió el probiótico que en el grupo control ( $p$ $=0,003$ ), lo que indica que la mucosa intestinal se había vuelto menos permeable. En este estudio en el grupo experimental el perímetro cefálico aumentó significativamente más $(1,1 \mathrm{~cm} /$ semana vs 0,9 cm/semana; $p=0,001)(10)$. Hay que tener en cuenta que este efecto fue observado en un intervalo de sólo 30 días y no se pudo determinar hasta cuando dicha diferencia se mantendría en el tiempo y si verdaderamente estaba asociada con la administración del probiótico. Por otra parte, es posible que la administración de Bifidobacterium Bb12 induzca cambios en la microbiota residente, lo que ha sido observado en prematuros y que sea la suma de la acción de la bacteria y de los cambios en los recuentos de otros componentes de la microbiota residente lo que verdaderamente explique estas modificaciones $(11,12)$. Desgraciadamente no se efectuaron controles a largo plazo para los parámetros antropométricos, mediciones que podrían haber arrojado luces acerca de estos aspectos.

Otros estudios han arrojado resultados discordantes en cuanto a los recuentos de bifidobacterias en las deposiciones, aunque se puede deber a que los ensayos han sido efectuados en recién nacidos de término; en un estudio, después de un alza considerable de los recuentos de bifidobacterias fecales durante los 5 primeros días (Ilegan al $65 \%$ ) se produjo a conti- 
nuación un descenso paulatino de manera que a las 16 semanas llegan al $55 \%$ y los recuentos fueron similares a los observados en los otros grupos experimentales. La administración de GOS/ FOS (galactooligosacáridos/fructooligosacáridos en proporción 90:10) se asocia con modificaciones del pH fecal, que a los 10 días es más bajo en los lactantes que reciben el Bifidobacterium Bb12 que en quienes reciben la fórmula control (13).

Gibson y colaboradores evaluaron el efectos de una fórmula infantil suplementada con Bifidobacterium animalis ssp lactis CNCM I-3446 y con los ácidos grasos esenciales docosahexaenoico (DHA) y araquidónico (AA). La elección de la cepa de Bifidobacterium estuvo basada en los resultados de su empleo en lactantes mayores y en preescolares, en tanto que las concentraciones de los ácidos grasos fueron similares a las detectadas en la leche de mujeres que consumen una dieta variada; además, estas concentraciones habían sido empleadas en otros estudios. Como objetivo principal se evaluó la ganancia de peso (gramos/día) entre los días 14 y 119 del seguimiento y como objetivos secundarios se estudiaron la longitud corporal acostado, el perímetro cefálico, el IMC, los títulos de anticuerpos circulantes, la tolerancia digestiva y los posibles eventos adversos; además se obtuvieron muestras de sangre para cuantificar otros parámetros bioquímicos. El estudio incluyó 72 niños en el grupo experimental y 70 en el grupo control. No se detectaron diferencias en las ganancias de peso aunque el grupo experimental consumió un mayor volumen de fórmula ni para los demás parámetros antropométricos. A los 119 días las concentraciones de DHA, AA y ácido eicosapentaenoico (EPA) en las membranas de los eritrocitos estaban aumentadas en los niños que consumieron el producto suplementado. Los demás parámetros bioquímicos fueron comparables en ambos grupos así como las respuestas a las inmunizaciones. Los niños del grupo experimental habrían presentado menos patologías intercurrentes durante el seguimiento (infecciones respiratorias altas, cutáneas o de la vía urinaria). Los autores concluyeron que no hubo diferencias entre los niños que recibieron el probiótico y los ácidos grasos poliinsaturados de cadena larga (LC-PUFAs) en relación con su crecimiento y las respuestas a las inmunizaciones (14). Estos resultados se pueden interpretar como que en los niños que tienen una alimentación adecuada y un estado nutricional normal los probióticos y los LC-PUFAs no aumentan sus parámetros por encima de sus respectivos rangos normales. Las respuestas a las inmunizaciones orales resultan potenciadas por los probióticos porque estimularían el sistema inmune de la mucosa intestinal, pero en este estudio las inmunizaciones fueron parenterales.

Las producción de IgA secretoria (IgAs) totales y de IgAs específica para diversos agentes fue evaluada por Holscher y colaboradores en un estudio en que participaron 172 lactantes sanos de 6 semanas de edad quienes recibieron una fórmula parcialmente hidrolizada que contenía Bifidobacterium Bb12 (10 $\mathrm{UFC} / g$ de polvo), con un grupo control que recibió la misma fórmula pero sin el probiótico (16). Como grupo paralelo se evaluó un grupo de lactantes amamantados que tenía similares parámetros antropométricos. El estudio se inició con la obtención de muestras fecales basales y a las 2 y 6 semanas. Las mediciones de IgAs específicas en heces tuvieron por objetivo detectar anticuerpos anti-poliomielitis y anti-rotavirus después de las respectivas inmunizaciones por vía oral. Se midió además la excreción fecal de calprotectina y de lactato y se cuantificó la presencia de Bb12 en las heces. El tipo de parto y la antropometría al nacer fueron comparables en los tres grupos. El volumen de fórmula prescrito resultó en un consumo de $10^{8}$ UFC/día de Bb12 a las 8 semanas y 1,1 × 108 UFC/día a partir de las 12 semanas. Bb12 fue detectado en las heces de $93 \%$ y $88 \%$ de los participantes del grupo experimental a las 2 y a las 6 semanas del estudio, respectivamente. No hubo diferencias en los recuentos del ADN bacteriano de bifidobacterias en las heces de los niños alimentados con fórmula con Bifidobacterium Bb12 y el grupo alimentado con leche materna, pero en ellos el número de copias de ADN de bifidobacteria fue mayor que en el grupo control. Los niños amamantados tenían niveles más elevados de IgAs fecal y los lactantes nacidos por parto vaginal que recibieron el probiótico desarrollaron niveles fecales crecientes de IgAs entre el nacimiento hasta los 6 meses de alimentación (entre V0 a V2) en comparación con aquellos alimentados con la fórmula convencional. Los niveles de IgAs fecal anti-poliovirus tendíeron a aumentar en los niños que recibieron Bifidobacterium lactis $\mathrm{Bb} 12$, al igual que los niveles de calprotectina, especialmente en quienes nacieron por cesárea. Por el contrario, los lactantes amamantados tuvieron niveles de calprotectina fecal más altos que los dos grupos alimentados con fórmula. De los lactantes que recibieron fórmula, aquellos que recibieron Bifidobacterium Bb12 tuvieron niveles de calprotectina fecal significativamente más altos a las 2 semanas del estudio que los que recibieron la fórmula convencional. En los lactantes amamantados el pH fecal fue más bajo que en los grupos que recibieron fórmulas y a las 2 semanas tendían a excretar más lactato en las heces. Algunos de los efectos de potenciación observados en los lactantes nacidos por vía vaginal que recibieron Bifidobacterium Bb12 se explicarían por el efecto aditivo del probiótico sobre la flora que adquirieron al pasar por el canal de parto. Es probable que otros resultados favorables que se observaron en este estudio sean el resultado de las ventajas que supone la colonización por una microbiota enriquecida con bifidobacterias. Según algunos autores existiría también una correlación entre los niveles de IgAs fecal y de calprotectina lo que esto estaría ligado con la disminución de las enfermedades asociadas con la presencia de IgE observada a partir de los 2 años de edad (16). La adición de Bifidobacterium Bb12 a una fórmula láctea representaría una manera de proporcionar un estímulo inmunomodulador a niños nacidos por cesárea o que no han sido amamantados.

Los efectos de $B$. animalis spp lactis $\mathrm{Bb} 12$ en prematuros fueron evaluados en una revisión sistemática de ensayos randomizados y con grupo control (17). Este análisis sostiene que la administración de Bifidobacterium animalis spp lactis se asocia con aumentos de las ganancias de peso aunque de baja magnitud cuya significancia en el largo plazo se desconoce. Esta revisión tampoco encontró mayor incidencia de sepsis con hemocultivos positivos para Bifidobacterium animalis spp lactis; sin embargo, la administración de este microorganismo habría tenido un efecto positivo porque su administración estuvo asociada con disminuciones del uso de antibióticos. Un estudio postuló que quienes recibieron $B$. lactis se habría producido un aumento de las infecciones nosocomiales pero la significancia estadística de los resultados estaba en límite y la densidad de infecciones (número de infecciones nosocomiales/número total de pacientes/día) no fue significativa en comparación con los controles $(18,19)$. Esta revisión tampoco encontró que los prematuros que recibieron Bifidobacterium animalis spp lactis hayan sufrido un mayor número de efectos adversos. Los autores postulan que el uso de Bifidobacterium animalis spp lactis debe ser motivo de optimismo aunque los resultados no parezcan enteramente convincentes. El efecto de esta bacteria en la prevención y el tratamiento de la ECN, 
en su evolución y en los resultados a mediano y largo plazo en cuanto a la mortalidad y secuelas graves debe ser investigado.

Los efectos de Bifidobacterium bifidum asociado con $S$. thermophilus fueron explorados por primera vez en un estudio acerca de la prevención de la adquisición intrahospitalaria de rotavirus y su transmisión en lactantes de entre 5 y 24 meses que habían sido admitidos para el manejo de cuadros crónicos. B. bifidum fue administrado en concentraciones de 1,9 $\times 10^{8}$ UFC/g de fórmula en polvo y $S$. thermophilus a razón de 0,14 $\times 10^{8} \mathrm{UFC} / \mathrm{g}$ de fórmula; la fórmula control era idéntica a la anterior pero sin los probióticos. El diseño de la investigación fue con estratificación por edad ( $<12$ meses, $\geq 12$ meses) y por la proporción de la energía diaria total que proporcionaba la fórmula ( $\leq 50 \%,>50 \%$ ). En el estudio fueron incluidos $47 \mathrm{ni}-$ ños (que registraron 57 admisiones) y se consignó información acerca de su estado nutricional y los episodios de diarrea si era pertinente. Durante los episodios de diarrea se efectuaron pruebas para detectar rotavirus, Salmonella, Shigella, Yersinia y Campylobacter. Además, independientemente de la presencia o no de diarrea se efectuaron controles microbiológicos fecales semanales. No hubo diferencias en los parámetros antropométricos o el número de días en que los participantes consumieron las respectivas fórmulas ni en los volúmenes consumidos. Un número significativamente menor de niños del grupo que recibió los probióticos experimentó episodios de diarrea y en ellos la frecuencia acumulada de días con esta patología fue también menor. Se detectó la presencia de rotavirus en siete episodios, cinco de ellos en el grupo control, y no se detectaron patógenos bacterianos. La incidencia acumulada de diarrea fue significativamente mayor en los lactantes del grupo control y en el grupo experimental se detectó una disminución de la excreción fecal de rotavirus (20).

\section{CONSIDERACIONES FINALES}

Existe una enorme bibliografía acerca de los probióticos y sus efectos que es el resultado de numerosas investigaciones en seres humanos y en modelos experimentales, y apoya la idea de que estos microorganismos ejercen acciones positivas sobre la salud humana; fundamentalmente a la potenciación de las inmunidades innata y adquirida, y las investigaciones han sido orientadas principalmente a patologías de las mucosas del tubo digestivo, el aparato respiratorio, de origen alérgico y el aparato genital femenino. Los probióticos más estudiados pertenecen a los géneros Lactobacillus y Bifidobacterium aunque también han sido estudiadas otras especies y cepas. Las patologías gastrointestinales más investigadas han sido la diarrea aguda, la diarrea del viajero, la diarrea asociada con el tratamiento con antibióticos, las diarreas persistentes asociadas con la desnutrición, la diarrea nosocomial y la diarrea infecciosa crónica. Otra patología en la que los probióticos han mostrado efectos positivos es la enterocolitis necrosante de los prematuros, respecto de la cual existe en la actualidad un consenso amplio acerca de los beneficios que aporta su uso. Se está estudiando la relación entre la microbiota residente y los probióticos en cuadros tales como el cólico de los lactantes, el síndrome del intestino irritable y el dolor abdominal periódico; los efectos positivos de diversas cepas de probióticos en estos cuadros ha sido sustanciado en investigaciones clínicas.

A nivel del aparato respiratorio hay evidencia de que algunos probióticos inducen acortamientos de la duración de las infecciones respiratorias altas, que requieren menos antibióticos para su manejo y que disminuyen la necesidad de ausentismos escolares y laborales. Otro aspecto que ha sido estudiado extensamente se refiere al efecto de lactobacilos y bifidobacterias como agentes moduladores de la inmunidad, especialmente a nivel de las mucosas y de la piel. En este sentido patologías más estudiadas son la atopia/eccema, respecto de la cual existe un alto nivel de consenso acerca de sus efectos benéficos manifestados por una menor superficie corporal afectada y menos prurito; también se ha publicado evidencia positiva acerca de los cuadros respiratorios y digestivos altos alérgicos en relación con la alergia estacional asociada en población local con el polen del cedro del Japón.

Una publicación del Comité de Nutrición de la Sociedad Europea de Gastroenterología, Hepatología y Nutrición (ESPGHAN) (21) manifestó que la administración de estos agentes no genera problemas relacionados con su inocuidad. Declaró que su administración a niños menores de 4 meses de edad no produce efectos clínicos consistentes. Sin embargo, es importante tener en cuenta que la leche materna aporta al lactante una microbiota compleja con altos recuentos de bacterias vivas que probablemente intervienen en la estimulación y maduración del sistema inmune del lactante y en la defensa de su tubo digestivo; estos microorganismos actuarían de manera semejante a los probióticos. En los lactantes que no pueden ser amamantados, la adición de probióticos a las fórmulas infantiles busca imitar y producir efectos similares al proceso natural ya que estimula la implantación de una microbiota con agentes reconocidamente inocuos, que probablemente tienen la capacidad de bloquear y desplazar a potenciales patógenos y alergenos a nivel de la superficie de la mucosa intestinal. Además, algunos probióticos sintetizan moléculas con propiedades antibióticas, como es el caso de la reuterina de $L$. reuteri.

El empleo de probióticos en leches acidificadas o como agentes aislados y adicionados a fórmulas o en bases oleosas o acuosas ya cumple 100 años y en los últimos 20 años su empleo a nivel mundial se ha masificado. Su uso se ha extendido libremente a todo tipo de grupos de población, a diversas edades y distintas patologías. La población realiza la mayoría de estos consumos sin control médico y sin tener conocimiento de la posible preexistencia de patologías; sin embargo, hasta ahora no han surgido señales de alarma. En las cepas en que se han descubierto en ellas plasmidios de resistencia a antibióticos éstas han sido descartadas o curadas de estos factores. Es evidente que, como con todo o agente biológico o fármaco, se debe mantener un seguimiento de sus efectos en la población. Es también importante aclarar si es posible complementar las capacidades funcionales de un probiótico mediante asociaciones con miembros de otras cepas, especies o incluso géneros. Los probióticos poseen cualidades cepaespecíficas y dentro de una misma especie una cepa podría poseer capacidades que se estimen altamente beneficiosas o, por el contrario, ser potencialmente indeseables o incluso peligrosas, por lo que es necesario realizar estudios cuidadosos. Estos riesgos potenciales son detectadas con mayor facilidad y precisión en la actualidad mediante métodos específicos de cultivo y técnicas moleculares que permiten conocer el genoma de las bacterias en todo su detalle.

El Comité de ESPGHAN concluye que el uso de probióticos no es recomendable en lactantes menores de 4 meses, pero esta afirmación debería estar basada en evidencias fisiológicas sólidas. Por lo demás, las bacterias presentes en la leche materna pertenecen a especies que son reconocidas como probióticos en la actualidad. Por otra parte, la investigación acerca de los efectos de los probióticos puede presentar ocasionalmente problemas particulares de diseño, incluso cuando los estudios están hechos por grupos experimentados como lo muestra el 
análisis del estudio de Wanke y Szajewska, en el que algunos factores no han sido analizados en todo su detalle (19).

Uno de los problemas respecto de muchas cepas de probióticos, que no vale para las tres que son discutidos en esta revisión, es que sólo hay uno o a lo más dos estudios con buena calidad metodológica y un número adecuado de sujetos, lo explica que las afirmaciones de la revisión de la literatura de ESPGHAN adquiera un cierto nivel de incertidumbre. Una publicación reciente sostiene que después de una revisión exhaustiva de la literatura no parece que hubiera aumentos de los riesgos asociados con el uso de los probióticos, que es difícil evaluar los efectos adversos, que se puede afirmar que si existen son muy poco frecuentes, y que la literatura de que se dispone tiene dificultades para contestar en forma tajante algunas de las dudas respecto de su inocuidad (22). Con todo, los probióticos son empleados por tal número de personas, sanas o enfermas con las más diversas patologías que cualquier manifestación adversa se habría hecho clínicamente evidente en los últimos 30 años. En Octubre de 2011 la Organización Mundial de Gastroenterología publicó una guía práctica que en sus lineamientos generales coincide con lo manifestado por la publicación citada anteriormente (23).

\section{RESUMEN}

Bifidobacterium animalis ssp lactis Bb12 es una de las cepaBifidobacterium animalis ssp lactis Bb12 es una de las cepas probióticas más estudiadas. Posee ventajas que la hacen útil para el uso industrial: tolerancia a ambientes ácidos y a temperaturas superiores a las de los demás probióticos. En un estudio de 12 meses Bifidobacterium animalis ssp lactis Bb12 fue administrada por un año asociada con $\mathrm{S}$. thermophilus y se observó que los niños experimentaron menos episodios de diarrea aguda. Estudios con seguimientos de distinta duración y diseño refrendaron estos resultados y su administración no ejercía influencias negativas en el crecimiento. Esta bifidobacteria inducía disminuciones de la excreción de rotavirus durante episodios de diarrea, lo que disminuye la posibilidad de contagios. Bifidobacterium animalis ssp lactis Bb12 ejerce efectos positivos sobre las manifestaciones de atopia como el eccema con el descenso de marcadores de inflamación tales como CD4 en el suero y de la proteína $X$ de los eosinófilos en la orina; y mejorías de las alteraciones de la permeabilidad. Estudios con Bifidobacterium animalis ssp lactis CNCM I-3446 administrada con ARA y DHA mostraron alteraciones de los parámetros de crecimiento y bioquímicos en lactantes y preescolares en seguimientos entre 14 y 119 días. La administración de Bifidobacterium animalis ssp lactis Bb12 junto con inmunizaciones se asociaba con niveles más elevados de slgA específica anti-poliovirus y de calprotectina, cuyos niveles estarían asociados con los de esta inmunoglobulina. Se ha sostenido que no existe justificación para administrar probióticos a menores de 4-6 meses no amamantados, el hecho que la leche materna los proporciona en cantidad y variedad apoya las posibles ventajas de su administración. Los probióticos protegerían no sólo de infecciones del tracto gastrointestinal sino también de las respiratorias altas. Hay casos aislados de sepsis en individuos con diversas afecciones, pero la proporción de afectados es mínima. No se han comunicado brotes epidémicos que indicarían cepas probióticas con capacidades invasoras. Probablemente no es aconsejable administrarlos a sujetos en shock o con defectos de la función de barrera intestinal. Los portadores de VIH y los pacientes con SIDA experimentan mejorías al recibir probióticos. En un estudio en Chile se demostró que aunque sin efectos clínicamente evidentes, administrar L. rhamnosus HN001 produjo aumentos del la IgA secretoria fecal, que representa un aumento de las defensas del tubo digestivo.

Palabras clave: Bifidobacterium animalis ssp lactis Bb12; diarrea aguda; inmunoglobulina A secretoria, inmunidad, virus de la inmunodeficiencia humana $(\mathrm{VIH})$, síndrome de inmunodeficiencia adquirida (SIDA).

\section{BIBLIOGRAFÍA}

1. Vernazza CL, Gibson GR, Rastall RA. Carbohydrate preference, acid tolerance and bile tolerance in five strains of Bifidobacterium. J Appl Microbiol. 2006; 100: 846-53.

2. Chouraqui JP, Van Egroo LD, Fichot MC. Acidified milk formula supplemented with Bifidobacterium lactis: impact on infant diarrhea in residential care settings. J Pediatr Gastroenterol Nutr. 2004; 38:288-92.

3. Saavedra JM, Abi-Hanna A, Moore N, Yolken RH. Longterm consumption of infant formulas containing live probiotic bacteria: tolerance and safety. Am J Clin Nutr. 2004; 79: 261-7.

4. Weizman Z, Asli G, Alsheikh A. Effect of a probiotic infant formula on infections in child care centers: comparison of two probiotic agents. Pediatrics 2005; 115: 5-9.

5. Weizman Z, Alsheikh A. Safety and tolerance of a probiotic formula in early infancy comparing two probiotic agents: a pilot study. J Am Coll Nutr 2006; 25: 415-9.

6. Shamir R, Makhoul IR, Etzioni A, Shehadeh N. Evaluation of a diet containing probiotics and zinc for the treatment of mild diarrheal illness in children younger than one year of age. J Am Coll Nutr 2005; 24: 370-5.

7. Mao M, Yu T, Xiong Y, Wang Z, Liu H, Gotteland M, Brunser $O$. Effect of a lactose-free milk formula supplemented with bifidobacteria and streptococci on the recovery from acute diarrhoea. Asia Pac J Clin Nutr 2008; 17: 30-4.

8. Erdoğan O, Tanyeri B, Torun E, Gönüllü E, Arslan H, Erenberk $U$, Oktem $F$. The comparition of the efficacy of two different probiotics in rotavirus gastroenteritis in children. J Trop Med. 2012;2012:787240. doi: 10.1155/2012/787240. Epub 2012 Jun 19.

9. Isolauri E, Arvola T, Sütas Y, Moilanen E, Salminen S. Probiotics in the management of atopic eczema. Clin Exp Allergy 2000; 30: 1604-10.

10. Stratiki Z, Costalos C, Sevastiadou S, Kastanidou O, Skouroliakou M, Giakoumatou A, Petrohilou V. The effect of a bifidobacter supplemented bovine milk on intestinal permeability of preterm infants. Early Hum Dev 2007; 83: 575-9.

11. Mohan R, Koebnick C, Schildt J, Mueller M, Radke M, Blaut M. Effects of Bifidobacterium lactis Bb12 supplementation on body weight, fecal $\mathrm{pH}$, acetate, lactate, calprotectin, and $\lg A$ in preterm infants. Pediatr Res. 2008; 64: 418-22.

12. Mohan R, Koebnick C, Schildt J, Schmidt S, Mueller M, Possner M, Radke M, Blaut M. Effects of Bifidobacterium lactis Bb12 supplementation on intestinal microbiota of preterm infants: a double-blind, placebo-controlled, randomized study. J Clin Microbiol 2006; 44): 4025-31.

13. Bakker-Zierikzee AM, Alles MS, Knol J, Kok FJ, Tolboom JJ, Bindels JG. Effects of infant formula containing a mixture of galacto- and fructo-oligosaccharides or viable Bifidobacterium animalis on the intestinal microflora during the first 4 months of life. Br J Nutr 2005; 94: 783-90.

14. Gibson RA, Barclay D, Marshall H, Moulin J, Maire JC, Makrides $M$. Safety of supplementing infant formula with long-chain polyunsaturated fatty acids and Bifidobacterium 
lactis in term infants: a randomised controlled trial. Br J Nutr 2009; 101: 1706-13.

15. de Vrese $M$, Rautenberg P, Laue C, Koopmans M, Herremans $T$, Schrezenmeir J. Probiotic bacteria stimulate virus-specific neutralizing antibodies following a booster polio vaccination. Eur J Nutr 2005; 44: 406-13.

16. Holscher HD, Czerkies LA, Cekola P, Litov R, Benbow M, Santema S, Alexander DD, Perez $V$, Sun S, Saavedra JM, Tappenden KA. Bifidobacterium lactis Bb12 enhances intestinal antibody response in formula-fed infants: a randomized, double-blind, controlled trial. JPEN J Parenter Enteral Nutr 2012; 36 (1 Suppl): 106S-17S.

17. Kukkonen K, Kuitunen M, Haahtela $T$, Korpela R, Poussa $T$, Savilahti E. High intestinal IgA associates with reduced risk of IgE-associated allergic diseases. Pediatr Allergy Immunol 2010; 21 (1 Pt 1): 67-73.

18. Szajewska H, Guandalini S, Morelli L, Van Goudoever JB, Walker A. Effect of Bifidobacterium animalis subsp lactis supplementation in preterm infants: a systematic review of randomized controlled trials. J Pediatr Gastroenterol Nutr 2010; 51: 203-9.

19. Ascher SB, Smith $P B$, Clark RH, Cohen-Wolkowiez M, Li JS, Watt K, Jacqz-Aigrain E, Kaguelidou $F$, Manzoni $P$, Benjamin DK Jr. Sepsis in young infants with congenital heart disease. Early Hum Dev 2012; 88 Suppl 2: S92-7.

20. Wanke M, Szajewska H. Lack of an effect of Lactobacillus reuteri DSM 17938 in preventing nosocomial diarrhea in children: a randomized, double-blind, placebo-controlled trial. J Pediatr. 2012; 161: 40-43

21. Braegger C, Chmielewska A, Decsi T, Kolacek S, Mihatsch W, Moreno L, Pieścik M, Puntis J, Shamir R, Szajewska $H$, Turck D, van Goudoever J; ESPGHAN Committee on Nutrition. Supplementation of infant formula with probiotics and/or prebiotics: a systematic review and comment by the ESPGHAN committee on nutrition. J Pediatr Gastroenterol Nutr. 2011; 52: 238-50.

22. Hempel $S$, Newberry $S$, Ruelaz $A$, Wang $Z$, Miles JNV, Suttorp MJ, Johnsen B, Shanman R, Slusser W, Fu N, Smith A, Roth E, Polak J, Motala A, Perry T, Shekelle PG. Safety of probiotics to reduce risk and prevent or treat disease. Agency for Healthcare Research and Quality. Evidence Report/Technology Assessment. Number 200. (Prepared by the Southern California Evidence-based Practice Center under Contract No. 290-2007-10062-I) AHRQ Publication No. 11-E007. Rockville Md: Agency for Healthcare Research and Quality. Abril de 2011.

23. WGO Practice Guideline. Probiotics and prebiotics. J Clin Gastroenterol. 2012; 46: 468-81. 